Faculdade de Medicina de Ribeirão Preto da Universidade de São Paulo

CAMILA DE AQUINO CRUZ

\title{
CARACTERIZAÇÃO DA DOR EM PACIENTES COM DISTROFIA FACIOESCAPULOUMERAL
}

Ribeirão Preto

2017 
Caracterização da dor em pacientes com distrofia facioescapuloumeral

Dissertação apresentada à Faculdade de Medicina de Ribeirão Preto da Universidade de São Paulo para obtenção de título de Mestre em

Neurologia e Neurociências Clínicas

Área de Concentração: Doenças CrônicoDegenerativas e Imunomediadas do Sistema Nervoso

Orientadora: Profa. Dra. Cláudia Ferreira da Rosa Sobreira

Ribeirão Preto 
(VERSO)

Dados Internacionais de Catalogação na Publicação (CIP)

Preparada pela Biblioteca da

Faculdade de Medicina de Ribeirão Preto da Universidade de São Paulo

Cruz, Camila de Aquino.

Caracterização da dor em pacientes com distrofia facioescapuloumeral. - Ribeirão Preto, 2017.

Dissertação (Mestrado Profissional) - Faculdade de Medicina de Ribeirão Preto da Universidade de São Paulo. Programa de Neurologia.

Orientadora: Cláudia Ferreira da Rosa Sobreira

Descritores: 1. Distrofia facioescapuloumeral 2. Dor 3. Fadiga 4. Incapacidades

Creprodução autorizada pelo autor 
Nome: Cruz, Camila de Aquino

Título: Caracterização da dor em pacientes com distrofia facioescapuloumeral

Dissertação apresentada à Faculdade de Medicina de Ribeirão Preto da Universidade de São Paulo para obtenção do título de Mestre em Neurologia e Neurociências Clínicas.

Aprovado em:

Banca Examinadora

Prof. Dr.: Instituição:

Julgamento: Assinatura:

Prof. Dr.: Instituição:

Julgamento: Assinatura:

Prof. Dr.: Instituição:

Julgamento: Assinatura: 


\section{AGRADECIMENTOS}

À profa. Claudia Ferreira da Rosa Sobreira, pela oportunidade de trabalhar ao seu lado, pela confiança e pelo apoio em todas as etapas de elaboração desse trabalho.

Ao professor Wilson Marques Junior, pelo exemplo e incentivo ao desenvolvimento de atividades acadêmicas.

Ao professor Amilton Antunes Barreira, pela oportunidade de fazer parte dessa instituição.

À professora Fabiola Dach pela ajuda na construção desse projeto.

À Dra Vanessa Daccach Marques, pelas orientações na construção da minha caminhada profissional e a quem serei eternamente grata.

Aos pacientes pela disponibilidade em comparecer para avaliações.

Aos amigos e colegas de trabalho Carolina Lavigne, André Cleriston, Patrícia Toscano, Pedro de Arruda Sampaio e Rodrigo Diniz pelo apoio, companheirismo e ensinamentos ao longo dessa caminhada.

À Valéria Brondi e à Sirlene Chaves pela ajuda imprescindível nas fases de convocação e coleta de dados.

À Priscila Colavite Papassidero pela disponibilidade em auxiliar na escolha dos instrumentos a serem utilizados nesse trabalho.

Aos amigos Pedro Ernesto, Emilia Bordini e Caroline Sposito pela amizade incondicional e por serem um porto seguro.

Aos meus pais, Fátima Aquino e Francisco Cruz, ao meu irmão Thiago Aquino, à minha afilhada Catarina Barbosa e à amiga Cosma Barbosa por serem a base de sustentação da minha existência física, emocional e espiritual.

Aos amigos e familiares, pelo constante estímulo ao crescimento profissional e pessoal. 


\section{RESUMO}

CRUZ, CA. Caracterização da dor em pacientes com distrofia facioescapuloumeral. 2017. Dissertação de mestrado. Faculdade de Medicina de Ribeirão Preto, Universidade de São Paulo, São Paulo, 2017.

INTRODUÇÃO: A distrofia facioescapuloumeral (DFEU) é uma desordem muscular de origem genética, que afeta primariamente músculos faciais, estabilizadores da escápula e músculos proximais dos membros superiores. A prevalência de dor na DFEU é elevada, entretanto, não há estudos que descrevam de forma mais detalhada esse sintoma. Estudo realizado em 2014 no nosso serviço constatou que a dor é um sintoma frequente e pode estar associada ao aumento de fadiga e incapacidades. OBJETIVOS: Realizar análise detalhada da dor em pacientes com DFEU e correlacionar os achados de intensidade da dor com dados demográficos, clínicos e laboratoriais. METODOLOGIA: Estudo observacional analítico transversal. Foram aplicadas ferramentas para caracterização clínica e de capacidade funcional desses pacientes, além de instrumentos específicos para avaliação de dor. RESULTADOS: Foram incluídos 25 pacientes, sendo o grupo com dor composto de 19 pacientes (76\%) e o grupo sem dor composto de 6 pacientes. Houve uma predominância de mulheres no grupo com dor $(84,2 \%)$. Não houve diferença entre a quantificação da força e os valores de creatinaquinase sérica (CK) nos grupos com e sem dor. Foi alta a prevalência de depressão e ansiedade associadas à DFEU. A pontuação na escala de fadiga e os escores associados às incapacidades foram maiores no grupo de pacientes com dor, entretanto não foi possível estabelecer uma relação entre essas variáveis. Constatou-se a presença de dor de moderada intensidade e com interferência também moderadamente importante nas atividades de vida diária. CONCLUSÕES: A dor é um sintoma relevante na DFEU, de caráter predominantemente focal e mais prevalente no sexo feminino. Há uma clara interferência da dor nas atividades de vida diária, entretanto, esse sintoma não se correlaciona com os demais parâmetros clínicos e laboratoriais (tempo de evolução da doença, força muscular, grau de incapacidade física e valor da CK).

PALAVRAS-CHAVE: distrofia facioescapuloumeral, dor, fadiga, incapacidades. 


\section{ABSTRACT}

CRUZ, CA. Characterization of pain in patients with facioescapuloumeral dystrophy. 2017. Dissertação de mestrado. Faculdade de Medicina de Ribeirão Preto, Universidade de São Paulo, São Paulo, 2017.

BACKGROUND: Facioescapuloumeral dystrophy (DFSH) is a genetic muscle disorder, which primarily affects facial muscles, scapula stabilizers and proximal muscles of the upper limbs. The prevalence of pain in DFSH is high, but there are no studies that describe this symptom in more detail. Study conducted in 2014 in our service found that pain is a frequent symptom and may be associated with increased fatigue and disability. OBJECTIVES: To perform a detailed analysis of pain in patients with DFHS and to correlate the findings of pain intensity with demographic, clinical and laboratory data. METHODOLOGY: Cross-sectional observational study. Tools were applied for clinical characterization and functional capacity of these patients, in addition to specific instruments for pain evaluation. RESULTS: Twentyfive patients were included, the pain group being composed of 19 patients (76\%) and the painless group composed of 6 patients. There was a predominance of women in the pain group $(84.2 \%)$. There was no difference between the quantification of strength and serum creatine kinase $(\mathrm{CK})$ values between groups. The prevalence of depression and anxiety associated with DFSH was high. Fatigue and disability scores were higher in the group of patients with pain, but it was not possible to establish a relationship between these variables. It was observed the presence of moderate intensity pain and also moderately important interference in the activities of daily living. CONCLUSIONS: Pain is a relevant symptom in DFSH, which is predominantly focal and more prevalent in females. There is a clear interference of pain in the activities of daily living, however, this symptom does not correlate with other clinical and laboratorial parameters (time of disease evolution, muscle strength, degree of physical disability and CK value

KEY-WORDS: facioescapuloumeral dystrophy, pain, fatigue, disabilities 


\section{LISTA DE TABELAS}

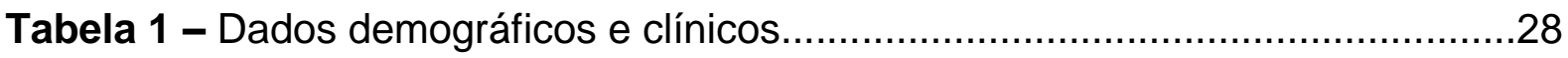

Tabela 2 - Escore somado do MRC e dosagens de CK...........................................32

Tabela 3 - Presença de depressão e ansiedade....................................................33

Tabela 4 - Intensidade de fadiga e grau de incapacidade nos grupos......................34

Tabela 5 - Quantificação da dor, da catastrofização e da sua interferência na

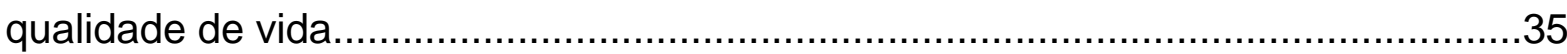




\section{LISTA DE SIGLAS}

BPI

Brief Pain Inventory

CK

Creatinaquinase sérica

DFEU

Distrofia facioescapuloumeral

DSM-5

Manual Diagnóstico e Estatístico de Transtornos Mentais

ENID

Escala Numérica de Intensidade de Dor (11 pontos)

FSS

Fatigue Severity Scale

IBM

Índice de Barthel Modificado

MRC

Medical Research Council

PCS

Pain Catastrophizing Scale 


\section{SUMÁRIO}

1. INTRODUÇÃO

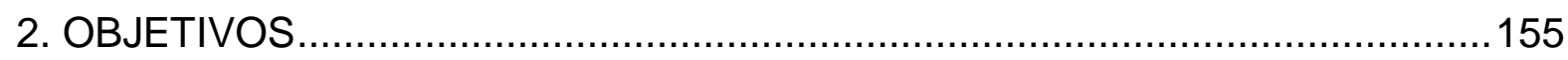

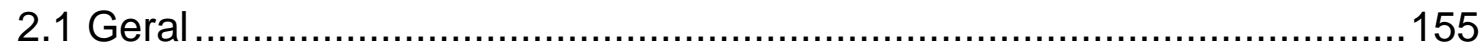

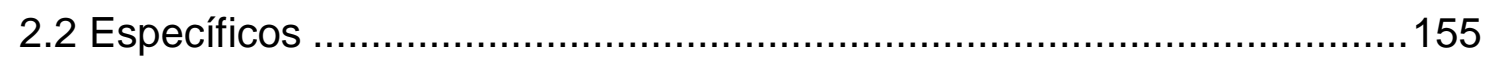

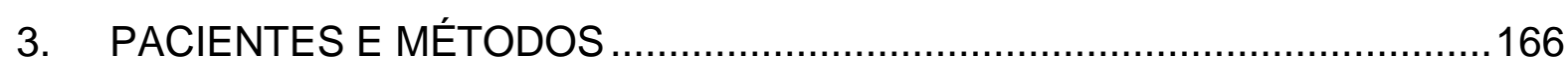

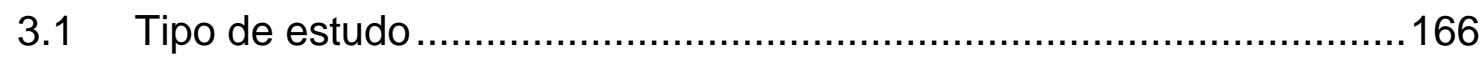

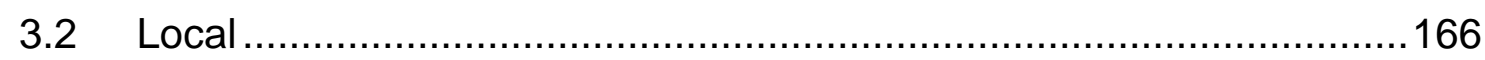

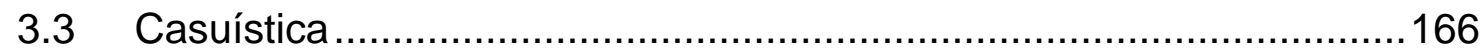

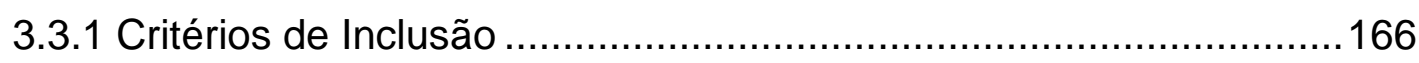

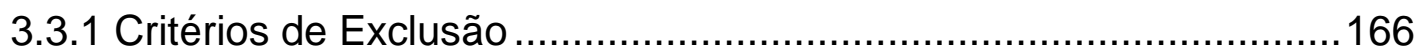

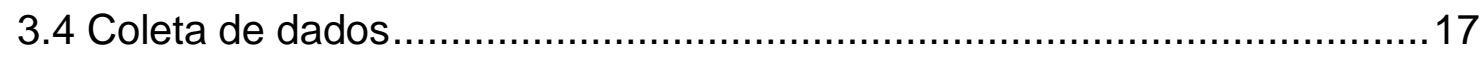

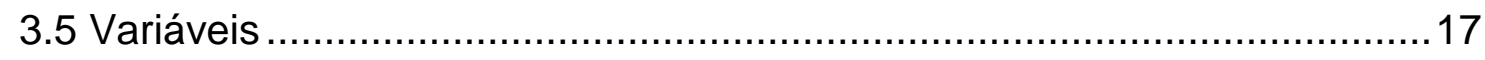

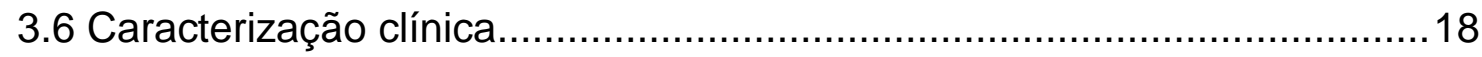

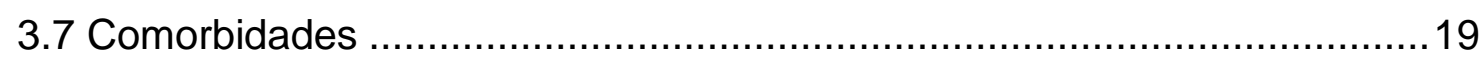

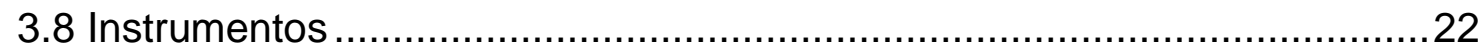

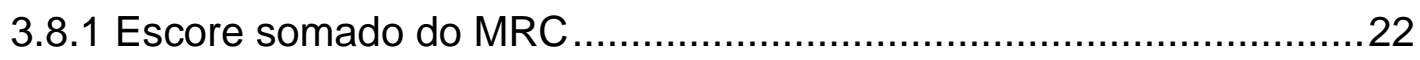

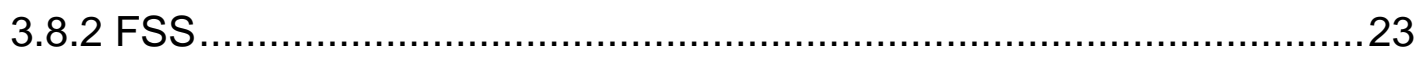

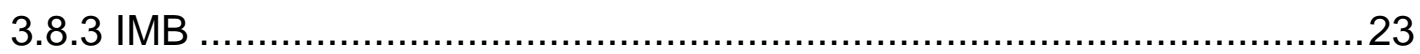

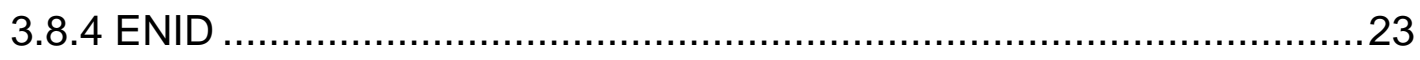

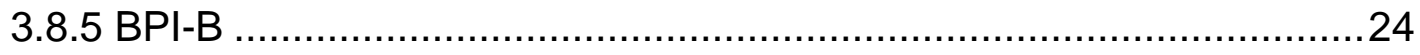

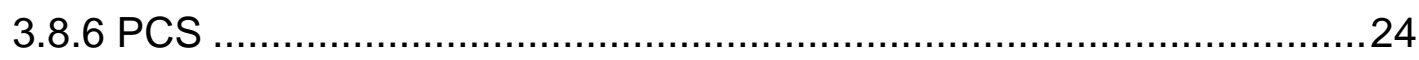

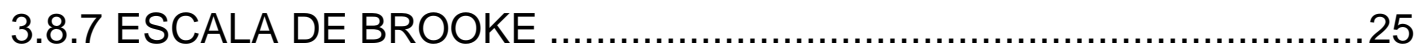




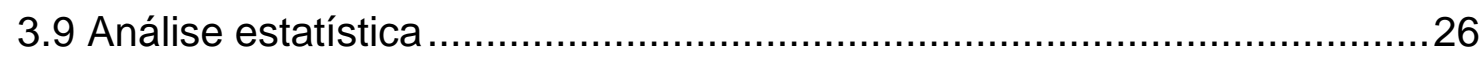

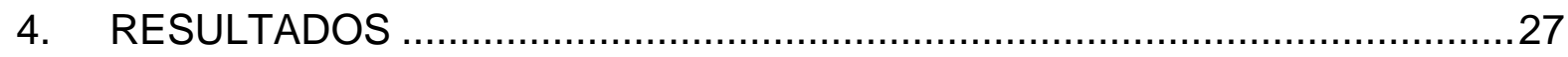

5. DISCUSSAO

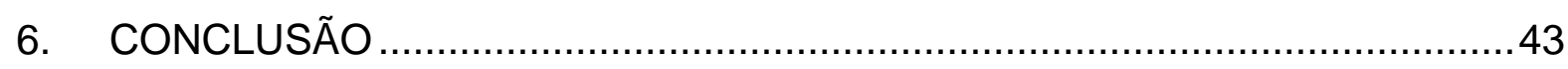

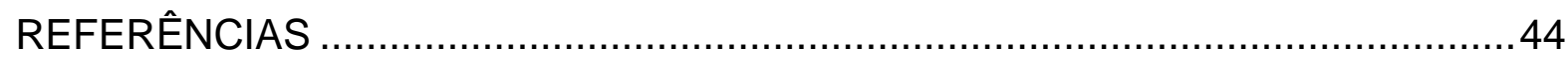

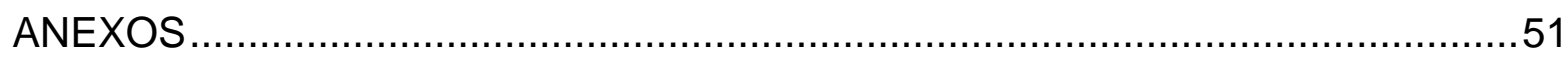

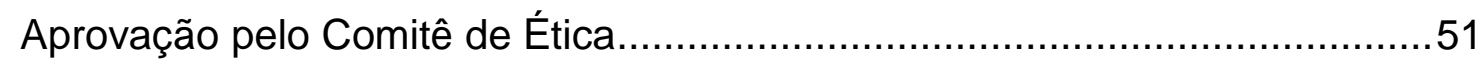

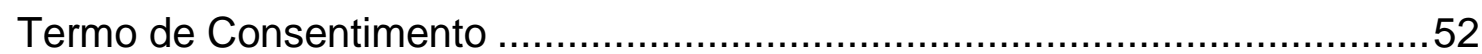

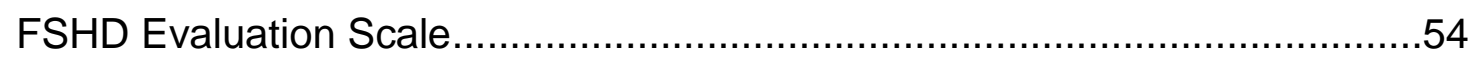

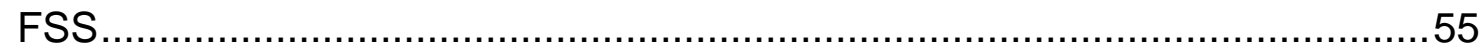

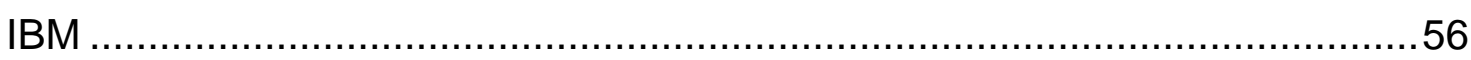

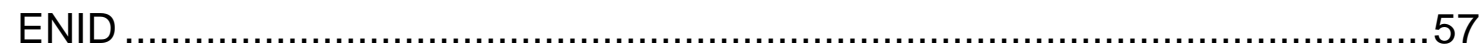

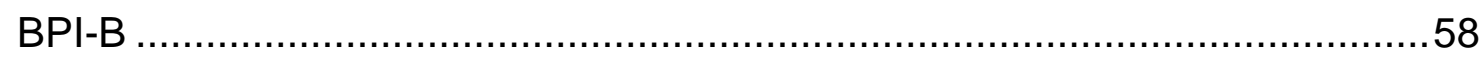

PCS …

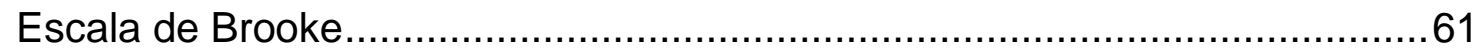

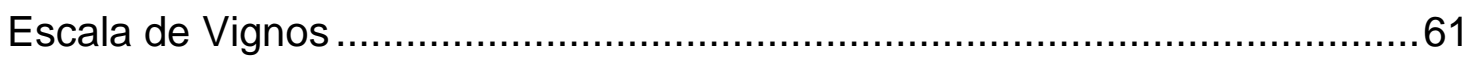




\section{INTRODUÇÃO}

A distrofia facioescapuloumeral (DFEU) é uma desordem muscular de origem genética. Referências sugerem a descrição de pacientes com quadro sugestivo dessa doença em 1862 e 1868 por Guillaume-Benjamin-Amand Duchenne (DUCHENNE, 1862; DUCHENNE, 1868, apud FLANIGAN, 2004, p. 1123). Entretanto, apenas em 1885 foi reconhecida como entidade nosológica distinta por Landouzy e Dejerine (LANDOUZY, 1885 apud FLANIGAN, 2004, p. 1123). Subsequentemente a doença foi denominada distrofia muscular forma LandouzyDejerine. O padrão autossômico dominante da doença, reconhecido por Landouzy e Dejerine, foi confirmado em publicações posteriores, a partir de 1933 (PEARSON, 1933 apud FLANIGAN, 2004, p. 1123). Somente a partir de 1990, estudos com bases moleculares passaram a ser desenvolvidos com o intuito de determinar a alteração genética e o cromossomo envolvido na gênese dessa doença (UPADHYAYA, 1990; WIJMENGA, 1991; WIJMENGA, 1992; GABELLINI, 2002).

A base genética da DFEU consiste da expressão do gene DUX4, normalmente suprimido, situado em uma região macrosatélite de 3,3 kilobases, chamada D4Z4, que se apresenta em múltiplas cópias na região subtelomérica do cromossomo 4 (4q35). Indivíduos normais apresentam de 11 a 100 repetições D4Z4 no cromossomo 4. Em aproximadamente $95 \%$ dos pacientes com DFEU, a contração do número dessas repetições para menos de 10 cópias leva ao remodelamento da cromatina e redução da metilação das citosinas na região, com consequente favorecimento à expressão gênica, ou seja, permitindo a transcrição do gene $D U X 4$. Sabe-se que quanto maior a contração do número de repetições D4Z4, mais grave tende a ser o quadro clínico. Fatores genéticos que regulam o estado de metilação do DNA também influenciam a gravidade do quadro. Há também evidência da relação entre o tamanho da deleção e a idade de início do quadro. Além disso, é característica dessa doença a ocorrência do fenômeno de antecipação, no qual se observa agravamento do quadro em gerações sucessivas (ZATZ, 1995).

A taxa de prevalência da DFEU é estimada em 10 a 20 por milhão (KILMER, 1995; EMERY, 1991).

Os sintomas da doença iniciam em média entre 3 e 44 anos, entretanto há relato de sintomas de início até 75 anos (PERSONIUS, 1994; VAN DER KOOI, 2000). 
A DFEU afeta músculos com distribuição relativamente específica. Geralmente o quadro inicia com fraqueza da musculatura facial, com acometimento dos músculos orbicular dos olhos, zigomático e orbicular da boca. Habitualmente os músculos extraoculares, masseter e temporal são poupados, assim como a musculatura faríngea. A fraqueza da face evolui de forma lentamente progressiva. Tipicamente há diparesia facial, que pode ser assimétrica e subclínica, com apagamento do sulco nasogeniano, dificuldade para ocluir completamente as pálpebras (por vezes, dorme com as pálpebras semicerradas), riso transversal e eversão do lábio inferior com lábio superior silente ("lábio de tapir"). Existem casos típicos da doença nos quais a musculatura facial não é acometida (KRASNIANSKI, 2003). A musculatura estabilizadora da escápula (músculos serrátil anterior, romboide, trapézio médio e latíssimo do dorso) já é acometida nos estágios iniciais da doença. O músculo deltoide geralmente é poupado nas fases iniciais da doença, mas poderá ser afetado com a progressão do quadro. Devido à fraqueza e atrofia desses músculos há rotação lateral e superior do ombro, deslocamento da escápula por fraqueza dos músculos que a fixam ("escápula alada"), além de acometimento de músculos proximais de membros superiores. Há uma fraqueza acentuada dos músculos bíceps e tríceps braquiais, associada à atrofia. Os músculos do antebraço geralmente são poupados. Alguns pacientes apresentam acometimento isolado da musculatura escapular (FELIZE, 2000). Além dessas regiões típicas descritas, pode haver acometimento de membros inferiores, com fraqueza predominante do músculo tibial anterior, podendo cursar com quedas (VAN DER KOOI, 2000). Os músculos gastrocnêmicos geralmente são poupados. $O$ acometimento muscular pode se estender para a musculatura pélvica, levando a uma postura em hiperlodose e alteração da marcha. Nos membros inferiores, o acometimento também pode ser assimétrico. Estima-se que em torno de $20 \%$ dos pacientes com distrofia facioescapuloumeral tornem-se cadeirantes com 0 evoluir da doença. Eventualmente, pode haver acometimento da musculatura abdominal. Geralmente não cursa com cardiopatia (STEVENSON, 1990). Em alguns casos, especialmente em crianças com acometimento mais grave, pode cursar com surdez neurossensorial e vasculopatia retiniana (FITZSIMONS, 1987; PADBERG, 1995).

Em descrições do quadro clínico de pacientes com DFEU a dor raramente é mencionada como uma característica clínica importante dessa doença; Bushby et al enfatizaram que a dor era um sintoma pouco relatado, mas de significativa 
importância na DFEU (BUSHBY, 1998). A dor é um sintoma subjetivo e, portanto, de difícil caracterização. Provavelmente em decorrência dessa dificuldade, a dor da DFEU tem sido foco de poucos estudos científicos até o momento.

Como citado acima, a ocorrência de dor na DFEU foi reconhecida como sintoma relevante há quase duas décadas, a partir do relato de quatro pacientes com DFEU nos quais a dor era o principal fator responsável pela incapacidade causada pela doença (BUSHBY, 1998). Entretanto, a partir de então, um número reduzido de estudos foi desenvolvido para analisar a dor na DFEU. Pesquisa dos termos "Facioscapulohumeral" e "pain" ou "FSHD" e "pain" em qualquer campo, na base de dados do PUBMED, resultou na identificação de 40 artigos científicos e um livro. Dos 40 artigos científicos, apenas 12 tinham a dor na DFEU ou nas doenças neuromusculares, incluindo a DFEU, como foco principal. O primeiro deles consiste nos relatos de caso citados acima (BUSHBY, 1998). Dos demais, apenas sete consistiram de estudos focados na caracterização da dor na DFEU, não havendo ainda uma conclusão a respeito da gênese da dor nessa doença (JENSEN, 2008; GUY-COICHARD, 2008; MIRÓ, 2009; PADUA, 2009; NIETO, 2012; MIRÓ, 2014; SMITH, 2014).

Foi realizado um estudo preliminar em nosso serviço que fez uma análise inicial da dor nesses pacientes (CRUZ, 2014). A análise dos resultados desse estudo revelou que a dor é um sintoma frequente na DFEU e provavelmente vem sendo subtratada. Em pacientes com doenças neuromusculares lentamente progressivas, como a DFEU, a dor crônica pode aumentar a incapacidade da doença, portanto consideramos essencial a extensão desse estudo.

Os ganhos relacionados ao estudo referem-se a uma melhor compreensão do sintoma dor na DFEU, que deverá contribuir para melhora das estratégias de tratamento e da qualidade de vida desses pacientes. 


\section{OBJETIVOS}

Para testar a hipótese de que a elevada frequência de dor nos pacientes com DFEU resulte de alterações relacionadas à fraqueza muscular, traçamos os seguintes objetivos:

\subsection{Geral}

- Realizar análise detalhada da dor em pacientes com DFEU.

\subsection{Específicos}

- Avaliar a dor em pacientes com DFEU;

- Correlacionar os achados de intensidade da dor com dados demográficos, clínicos e laboratoriais. 


\section{PACIENTES E MÉTODOS}

\subsection{Tipo de estudo}

Observacional Analítico Transversal

\subsection{Local}

Ambulatório de doenças neuromusculares do Hospital das Clínicas da Faculdade de Medicina de Ribeirão Preto da Universidade de São Paulo (HCFMRPUSP).

\subsection{Casuística}

Foram recrutados todos os pacientes com diagnóstico clínico de DFEU que são acompanhados no ambulatório de doenças neuromusculares (miopatias) do HCFMRP-USP.

\subsubsection{Critérios de Inclusão}

- Distrofia muscular com fraqueza de distribuição facioescapuloumeral;

- Padrão de herança autossômico dominante.

\subsubsection{Critérios de exclusão}

- Diagnóstico confirmado de outra desordem neuromuscular que justifique os sintomas;

- Presença de comorbidades que cursem com dor 


\subsection{Coleta de dados}

- Revisão prévia de prontuário para obtenção de dados cadastrais e informações clínicas relevantes sobre o início e evolução da doença, assim como valores de creatinaquinase sérica. Foram pesquisados também resultados de exames complementares, como eletroneuromiografia e biópsia muscular.

- Após aceitação de participação no estudo e assinatura do TCLE, foi realizada uma avaliação clínica com realização de exame neurológico completo, aplicação das escalas clinimétricas previamente estabelecidas e classificação clínica da DFEU. Todas as avaliações foram realizadas por um neurologista com formação adicional em doenças neuromusculares.

\subsection{Variáveis}

- Idade de início dos sintomas motores e na data da avaliação;

- Tempo de evolução da doença;

- Sexo;

- Escolaridade;

- Presença de dor;

- Classificação clínica;

- Avaliação de depressão e ansiedade;

- Quantificação da força muscular;

- Creatinaquinase sérica;

- Eletroneuromiografia;

- Pontuação da dor, da catastrofização associada à dor, da capacidade funcional e da fadiga nas escalas aplicadas;

- Tratamentos (atuais e prévios) realizados. 


\subsection{Caracterização clínica}

A classificação dos pacientes em diferentes formas clínicas da DFEU foi realizada de acordo com Ricci et al (RICCl, 2016). Essa classificação é baseada em quatro seções. Na primeira seção, é avaliada história clínica, incapacidades e grupos musculares afetados utilizando a escala MRC (Escore da Medical Research Council). A avaliação dos grupos musculares é subdividia em seis seções independentes que avaliam força e funcionalidade dos músculos da face (escore variando de zero a dois), da cintura escapular (escore variando de zero a três), dos membros superiores (escore variando entre zero e dois), dos músculos distais de membros inferiores (escore variando de zero a dois), da cintura pélvica (escore variando de zero a cinco) e da musculatura abdominal (escore variando de zero a um) (LAMPERTI, 2010). As outras três seções incluem formulários específicos que são a Escala de Avaliação da DFEU, o Formulário de Diagnóstico Clínico e Categorias Clínicas (RICCI, 2013; RICCI, 2014; NIKOLIC, 2016; LAMPERTI, 2010). São considerados achados incomuns, ptose palpebral, fenômenos miotônicos, ondulações musculares (tipo "rippling"), fraqueza da musculatura ocular extrínseca, dos músculos da faringe e da língua, contraturas precoces, pés cavos, cabeça caída, mioglobinúria e níveis de creatinaquinase persistentemente elevados. Após a aplicação de todas essas ferramentas, são caracterizados nove fenótipos da DFEU (RICCI, 2016). A categoria A subdivide-se em três grupos. São classificados como A1 pacientes com paresia facial grave (com incapacidade de fechar ambos os olhos e de protruir os lábios), comprometimento da abdução dos membros superiores e escápula alada (com escore DFEU escapular de um) e ausência de achados incomuns. Na categoria A2, estão pacientes com paresia facial (acometendo os andares superior e inferior da face), comprometimento da abdução dos membros superiores e escápula alada (com escore DFEU escapular maior ou igual a um) e ausência de achados incomuns. Na categoria A3, estão os pacientes com paresia facial (com acometimento de andar superior ou inferior da face), comprometimento da abdução dos membros superiores e escápula alada (com escore DFEU escapular maior ou igual a um) e ausência de achados incomuns. A categoria B subdivide-se em dois grupos. São classificados como B1 pacientes com comprometimento da abdução dos membros superiores com escápula alada (com escore DFEU escapular 
maior ou igual a um), ausência de paresia facial e ausência de achados incomuns. $\mathrm{Na}$ categoria B2, estão pacientes com paresia facial (escore DFEU facial maior ou igual a um), ausência de comprometimento da abdução dos membros superiores e ausência de achados incomuns. A categoria $\mathrm{C}$ subdivide-se em dois grupos. $\mathrm{Na}$ categoria $\mathrm{C} 1$, estão pacientes com presença de pelo menos um sinal clínico típico da doença, mas com escore DFEU de zero. Na categoria C2, estão pacientes sem sinais de fraqueza muscular e pontuação de zero no escore DFEU. A categoria $D$ subdivide-se em dois grupos. São classificados como D1 pacientes que fecham critérios para as categorias A1, A2, A3, B1 e B2, mas que apresentam pelo menos um dos achados incomuns. Por fim, são classificados como D2 pacientes que fecham critérios para as categorias $\mathrm{C} 1$ ou $\mathrm{C} 2$, mas que apresentam pelo menos um dos achados incomuns e pacientes que não fecham critérios para nenhuma das categorias acima.

\subsection{Comorbidades}

Foram aplicados critérios diagnósticos de depressão e ansiedade, de acordo com o Manual Diagnóstico e Estatístico de Transtornos Mentais (DSM-5). (ARLINGTON, 2013).

Os critérios utilizados para diagnóstico de Transtorno Depressivo Maior foram:

A. Cinco (ou mais) dos seguintes sintomas estiveram presentes durante o mesmo período de duas semanas e representam uma mudança em relação ao funcionamento anterior; pelo menos um dos sintomas é (1) humor deprimido ou (2) perda de interesse ou prazer.

Nota: não incluir sintomas nitidamente devidos a outra condição médica.

1. Humor deprimido na maior parte do dia, quase todos os dias, conforme indicado por relato subjetivo (p.ex., sente-se triste, vazio, sem esperança) ou por observação feita por outras pessoas (p.ex., parece choroso). (Nota: em crianças e adolescentes, pode ser humor irritável.)

2. Acentuada diminuição do interesse ou prazer em todas ou quase todas as atividades na maior parte do dia, quase todos os dias 
(indicada por relato subjetivo ou observação feita por outras pessoas).

3. Perda ou ganho significativo de peso sem estar fazendo dieta ( $p$. ex., uma alteração de mais de $5 \%$ do peso corporal em um mês), ou redução ou aumento do apetite quase todos os dias. (Nota: em crianças, considerar o insucesso em obter ganho de peso esperado).

4. Insônia ou hipersonia quase todos os dias.

5. Agitação ou retardo psicomotor quase todos os dias (observáveis por outras pessoas, não meramente sensações subjetivas de inquietação ou de estar mais lento).

6. Fadiga ou perda de energia quase todos os dias (Nota: esse critério não foi considerado, tendo em vista que pode estar associado à DFEU).

7. Sentimentos de inutilidade ou culpa excessiva ou inapropriada (que podem ser delirantes) quase todos os dias (não meramente autorrecriminação ou culpa por estar doente).

8. Capacidade diminuída para pensar ou se concentrar, ou indecisão, quase todos os dias (por relato subjetivo ou observação feita por outras pessoas).

9. Pensamentos recorrentes de morte (não somente medo de morrer), ideação suicida recorrente sem um plano específico, um tentativa de suicídio ou plano específico para cometer suicídio.

B. Os sintomas causam sofrimento clinicamente significativo ou prejuízo no funcionamento social, profissional ou em outras áreas importantes da vida do indivíduo.

C. O episódio não é atribuível aos efeitos fisiológicos de uma substância ou a outra condição médica.

Nota: os critérios $A-C$ representam um episódio depressivo maior.

D. A ocorrência do episódio depressivo maior não é mais bem explicada por transtorno esquizoafetivo, esquizofrenia, transtorno esquizofreniforme, transtorno delirante, outro transtorno do espectro da esquizofrenia e outro transtorno psicótico especificado ou transtorno da esquizofrenia e transtorno psicótico não especificado. 
E. Nunca houve um episódio maníaco ou episódio hipomaníaco.

Nota: essa exclusão não se aplica se todos os episódios do tipo maníaco ou do tipo hipomaníaco são induzidos por substância ou são atribuíveis aos efeitos psicológicos de outra condição médica.

Os critérios utilizados para diagnóstico de Transtorno de Ansiedade Generalizada foram:

A. Ansiedade e preocupação excessivas (expectativa apreensiva), ocorrendo na maioria dos dias por pelo menos seis meses, com diversos eventos ou atividades (tais como desempenho escolar ou profissional).

B. O indivíduo considera difícil controlar a preocupação.

C. A ansiedade e a preocupação estão associadas com três (ou mais) dos seguintes seis sintomas (com pelo menos alguns deles presentes na maioria dos dias nos últimos seis meses).

Nota: apenas um item é exigido para crianças.

1. Inquietação ou sensação de estar com os nervos à flor da pele.

2. Fatigabilidade.

Nota: esse critério não foi considerado, tendo em vista que pode estar associado à DFEU.

3. Dificuldade em concentrar-se ou sensações de "branco" na mente.

4. Irritabilidade.

5. Tensão muscular.

6. Perturbação do sono (dificuldade em conciliar ou manter o sono, ou sono insatisfatório e inquieto).

D. A ansiedade, a preocupação ou os sintomas físicos causam sofrimento clinicamente significativo ou prejuízo no funcionamento social, profissional ou em outras áreas importantes da vida do indivíduo.

E. A perturbação não se deve aos efeitos fisiológicos de uma substância ( $p$. ex. droga de abuso, medicamento) ou a outra condição médica (p. ex., hipotireoidismo).

F. A perturbação não é mais bem explicada por outro transtorno mental ( $p$. ex., ansiedade ou preocupação quanto a ter ataques de pânico no transtorno de pânico, avaliação negativa no transtorno de ansiedade social 
[fobia social], contaminação ou outras obsessões no transtorno obsessivocompulsivo-compulsivo, separação das figuras de apego no transtorno de ansiedade de separação, lembranças de eventos traumáticos no transtorno de estresse pós-traumático, ganho de peso na anorexia nervosa, queixas físicas no transtorno de sintomas somáticos, percepção de problemas na aparência no transtorno dismórfico corporal, ter uma doença séria no transtorno de ansiedade de doença ou o conteúdo de crenças delirantes na esquizofrenia ou transtorno delirante

\subsection{Instrumentos}

\subsection{1: ESCORE SOMADO DA ESCALA DO MEDICAL RESEARCH COUNCIL (ESCORE SOMADO DO MRC)}

O escore somado do MRC é a soma das escalas MRC de seis grupos musculares: abdutores do ombro, flexores do cotovelo, extensores do punho, flexores do quadril, extensores do joelho e dorsiflexores dos pés de ambos os lados, variando de 60 (normal) até 0 (tetraplégico). (SILVA, 2006; KLEYWEG, 1991).
0: Ausência de contração visível
1: Contração visível sem movimento do membro
2: Movimento ativo do membro, mas não contra a gravidade
3: Movimento ativo contra a gravidade completando o movimento articular
4: Movimento ativo contra a gravidade e resistência
5: Força normal 


\subsection{2: ESCALA DE GRAVIDADE DA FADIGA (FATIGUE SEVERITY SCALE - FSS)}

A escala de gravidade da fadiga avalia a perda subjetiva de energia física ou mental, relatada pelo paciente, que interfere nas suas atividades diárias. Tal instrumento foi validado para o português para uso em pacientes com esclerose múltipla (GOMES, 2011) e em nosso serviço para aplicação em pacientes com miopatia (TOLEDO, 2012). Os itens são graduados a partir de uma escala numérica que varia de 1 a 7 , com pontuação mínima de 9 (sem sinais de fadiga) e máxima de 63 (fadiga incapacitante).

\subsection{3: ÍNDICE DE BARTHEL MODIFICADO (IBM)}

O Índice de Barthel Modificado é um índice absoluto que quantifica o grau de dependência funcional. Os itens são pontuados numa escala numérica que varia de 1 a 5 (quanto menor a pontuação, maior o grau de dependência). $O$ índice varia de 10 (dependência total) a 50 (independência total). Tal instrumento fornece dados quantitativos e qualitativos para avaliação de incapacidades (SHAH, 1989; CINCURA, 2009).

\subsection{4: ESCALA NUMÉRICA DE INTENSIDADE DE DOR DE 11 PONTOS (ENID)}

A Escala Numérica de Intensidade de Dor de 11 pontos é amplamente utilizada no Brasil e gradua os diferentes níveis de dor. O paciente deve escolher entre 11 números, de 0 (sem dor) a 10 (pior dor possível), de acordo com a dor apresentada. A escala pode ser aplicada gráfica ou verbalmente (JENSEN, 1986; JENSEN, 1994). No presente estudo, o paciente graduou a dor no momento da avaliação. 


\subsection{5: PEQUENO QUESTIONÁRIO SOBRE DOR (BRIEF PAIN INVENTORY ADAPTADO PARA O PORTUGUÊS FALADO NO BRASIL (BPI-B) $)^{2}$}

Esse instrumento avalia a intensidade da dor (através de 4 itens com pontuação máxima possível de 40) e interferência da dor nas atividades do cotidiano (7 itens com pontuação máxima possível de 70). Escores mais altos indicam dor mais forte e maior interferência na vida diária. Esse instrumento foi validado no nosso serviço para avaliação de dor em pacientes com miopatia (TOLEDO, 2008).

\subsection{6: ESCALA DE PENSAMENTOS CATASTRÓFICOS SOBRE DOR (PAIN CATASTROPHIZING SCALE - PCS)}

Entende-se por catastrofização o conjunto de pensamentos negativos exagerados, durante experiências dolorosas reais ou previstas. O questionário da escala de pensamentos catastróficos inclui 13 itens que descrevem um conjunto de pensamentos, percepções ou sentimentos associados à dor (JUNIOR, 2008). A escala avalia aspectos de desesperança, magnificação e ruminação. É solicitado que os pacientes respondam às questões de acordo com os pensamentos e sentimentos que desenvolvem quando acometidos por dor (independente de estar ou não com dor no momento da entrevista). Os itens são graduados a partir de uma escala numérica de classificação de 5 pontos ( 0 a 4). A pontuação varia de 0 a $52 \mathrm{e}$ quanto maior o escore, maior o catastrofismo. A avaliação do grau de catastrofização é importante, pois pode estar relacionado com reatividade fisiológica da estimulação dolorosa e, portanto, funcionar como mecanismo de amplificação de dor. Foi demonstrada associação de catastrofização e aumento de marcadores biológicos pró-inflamatórios (SEHN, 2012; SEHN, 2012). 


\subsection{7: ESCALA DE BROOKE}

A escala de Brooke (BROOKE, 1999; BROOKE, 1981) é validada para uso em miopatias e distrofias (incluindo DFEU) e avalia a funcionalidade para membros superiores e atividades de vida diária. O paciente é classificado em um dos seis itens: 1- Inicia com os membros superiores ao lado do corpo, é capaz de abduzir os braços em uma amplitude de movimento completa até alcançar acima da cabeça; 2É capaz de levantar os braços acima da cabeça apenas flexionando os cotovelos (diminuindo a amplitude de movimento) ou usando músculos acessórios; 3- Não é capaz de levantar as mãos acima da cabeça, mas pode levantar um copo de água de $237 \mathrm{ml}$ até a boca (usando ambas as mãos se necessário); 4- É capaz de levar a mão à boca, mas não é capaz de levantar um copo de água de $237 \mathrm{ml}$ até a boca; 5 Não é capaz de levar a mão à boca, mas pode usar a mão para segurar uma caneta ou pegar moedas em cima da mesa; 6- Não é capaz de levar a mão à boca, não possui função com as mãos. Quanto maior a pontuação, maior o acometimento dos membros superiores e maior a repercussão nas atividades de vida diária.

\subsection{8: ESCALA DE VIGNOS}

A escala de Vignos é validada para uso em miopatias e distrofias (incluindo DFEU) e avalia a funcionalidade para membros inferiores, levanto em consideração aspectos como equilíbrio e mobilidade (VIGNOS, 1963). O paciente é classificado em um dos dez itens: 1- Deambula e sobe escadas sem auxílio; 2- Deambula e sobe escadas com ajuda de corrimão; 3- Deambula e sobe escadas vagarosamente, com ajuda de corrimão (mais de 25 segundos para 8 degraus); 4- Deambula sem assistência e levanta da cadeira, mas não consegue subir escadas; 5- Deambula sem assistência, mas não consegue levantar da cadeira ou subir escadas; 6Deambula somente com auxílio ou deambula independentemente com tutor longo; 7 Deambula com tutor longo, mas requer auxílio para manter o equilíbrio; 8Permanece na posição ortostática com o tutor longo, mas não é capaz de andar sem auxílio; 9- Confinado à cadeira de rodas; 10- Confinado ao leito. Quanto maior a pontuação, maior o acometimento dos membros inferiores e maior a repercussão nas atividades de vida diária. 


\subsection{Análise Estatística}

Os dados foram apresentados com medidas de tendência central e dispersão, através da média e do desvio padrão. A análise estatística para determinar se os resultados respeitam ou não uma curva de distribuição normal foi realizada através do teste de Kolmogorov-Smirnov.

A comparação dos parâmetros demográficos e clínicos entre os pacientes DFEU com dor e sem dor foi realizada pelo teste de Mann-Whitney. As variáveis categóricas binárias foram avaliadas através do teste exato de Fisher.

A comparação da dor de acordo com a classificação clínica da DFEU foi realizada pelo teste de Kruskal-Wallis.

A análise de correlação dos parâmetros clínicos foi realizada através do cálculo do coeficiente de correlação de Spearman. Os critérios de correlação adotados foram: $\leq 0.20$ muito baixo; $0.21-0.40$ baixo; $0.41-0.60$ moderado; $0.61-0.80$ alto; $0.81-$ 1.0 muito alto (AJZEN, 1998).

O nível de significância foi estabelecido em $p \leq 0,05$. 


\section{RESULTADOS}

Foram convocados para avaliação 35 pacientes seguidos no ambulatório de miopatias do HCFMRP-USP. Desses, cinco pacientes não puderam comparecer. Foi então avaliado um total de 30 pacientes.

Dos 30 pacientes avaliados, cinco pacientes não preencheram critérios de inclusão, não sendo incluídos nesse estudo.

Dos 25 pacientes incluídos, 12 (48\%) apresentavam confirmação molecular da doença em exame próprio ou de algum familiar acometido. Os outros 13 pacientes (52\%) receberam o diagnóstico de DFEU pela presença de distrofia de distribuição facioescapuloumeral e padrão de herança autossômico dominante.

Do total de 25 pacientes do estudo, 19 (76\%) apresentavam dor e 6 (24\%) não relataram esse sintoma (gráfico 1).

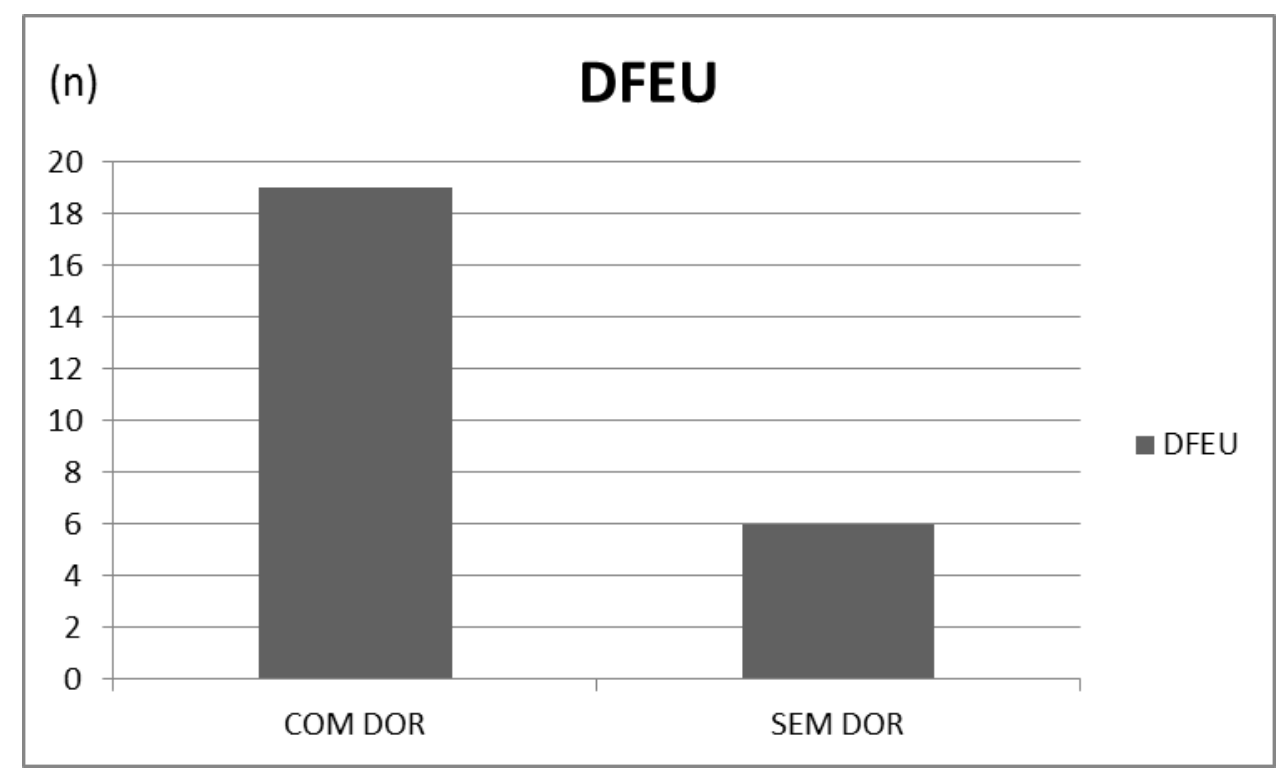

Gráfico 1: Pacientes com diagnóstico de DFEU com dor e sem dor. No eixo das ordenadas está representado o número de pacientes.

Foi realizado teste de normalidade para todas as variáveis e a maioria não apresentou distribuição normal. Em virtude disso, e pelo fato de o grupo de pacientes sem dor possuir uma quantidade pequena de indivíduos, as análises estatísticas foram realizadas através de testes não paramétricos. 
A tabela 1 apresenta os dados demográficos e algumas características clínicas, de acordo com a subdivisão em grupos de pacientes com DFEU com dor e sem dor. Podemos observar que não houve diferença significativa na idade no momento da avaliação $(p=0,77)$, na idade de início dos sintomas $(p=0,54)$ e no tempo de evolução da doença $(p=0,82)$. O nível de escolaridade também foi semelhante entre os grupos $(p=0,53)$.

Tabela 1: Dados demográficos e clínicos

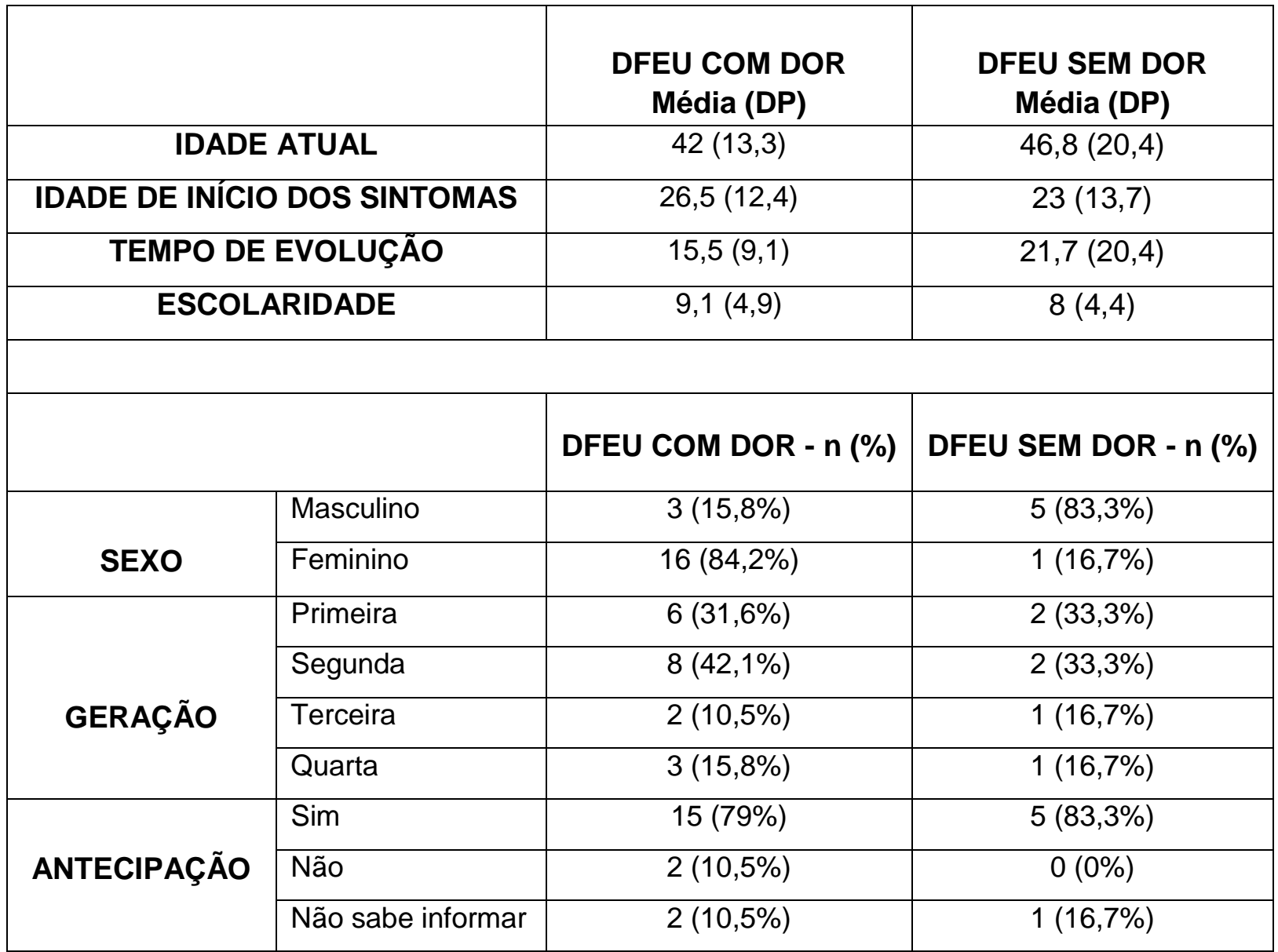

n: número de pacientes/ DP: Desvio Padrão

No grupo de pacientes com dor, houve predomínio de indivíduos do sexo feminino $(84,2 \%)(p=0,006)$. 
Os resultados da classificação clínica da DFEU, realizada de acordo com a proposta de Ricci et al. (2016), estão apresentados no Gráfico 2. Todos os nossos pacientes foram classificados em quatro dentre os nove possíveis subgrupos de categorias clínicas. A princípio, não houve diferença nos parâmetros idade na avaliação $(p=0,07)$, idade de início dos sintomas $(p=0,09)$ ou tempo de evolução da doença $(p=0,17)$ entre esses subgrupos.

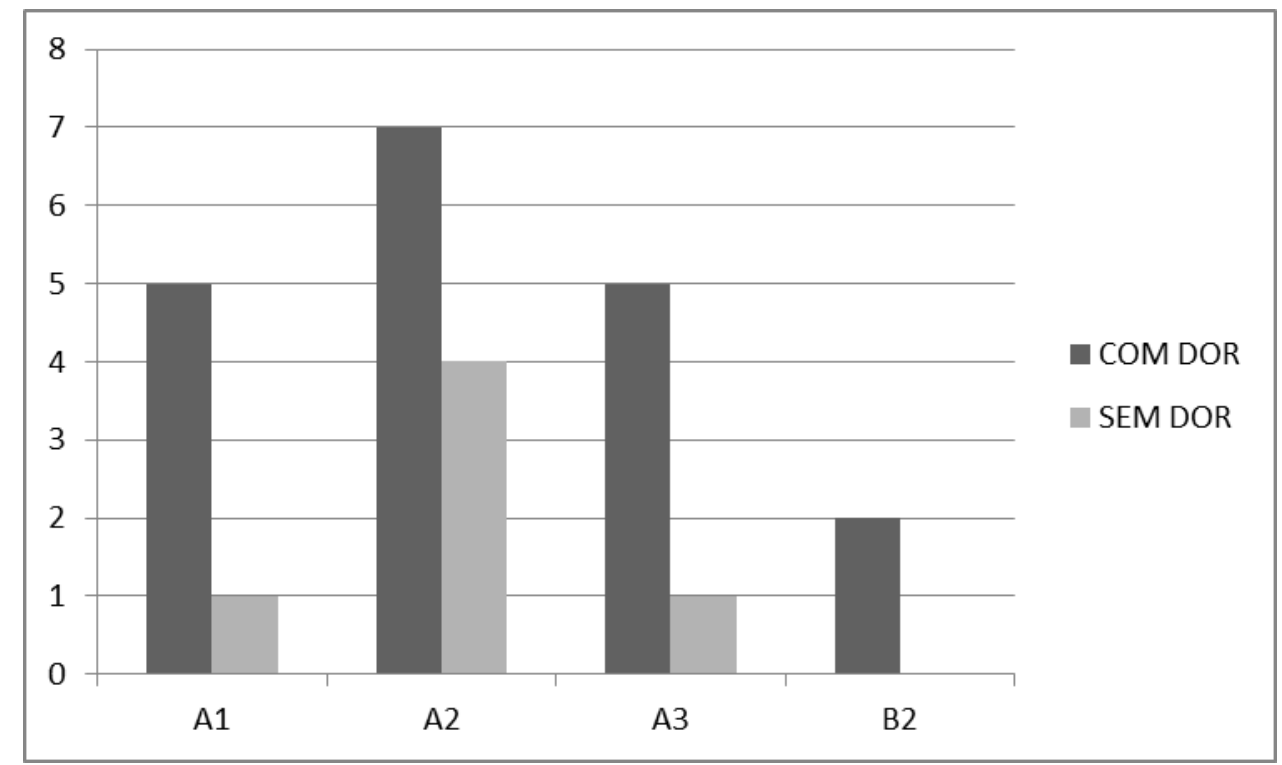

Gráfico 2: Classificação clínica dos pacientes com DFEU. No eixo das ordenadas está representado o número de pacientes.

No gráfico 3 são apresentados dados relacionados à força dos membros superiores dos pacientes com dor (gráfico 3.1) e sem dor (gráfico 3.2) de acordo com o escore somado do MRC. O gráfico 4 mostra a distribuição de força nos membros inferiores nos pacientes com dor (gráfico 4.1) e sem dor (gráfico 4.2) também de acordo com o escore somado do MRC. As séries foram marcadas em um espectro de cores, sendo a força grau 0 representada pela cor mais escura do gráfico e a força grau 5 representada pela cor mais clara do gráfico. As forças de grau 1, 2, 3 e 4 foram representadas graficamente por cores intermediárias. 


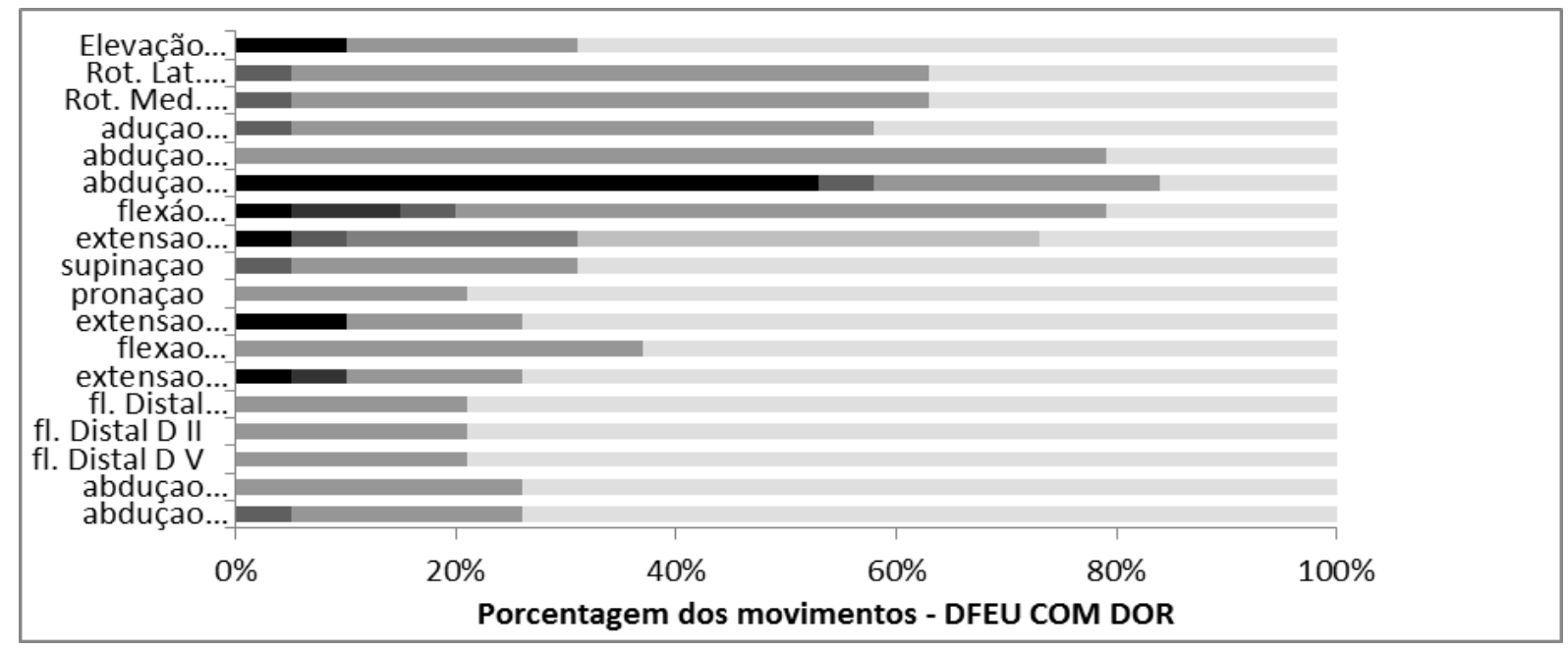

\section{Gráfico 3.1: Distribuição de força em membros superiores nos pacientes com dor}

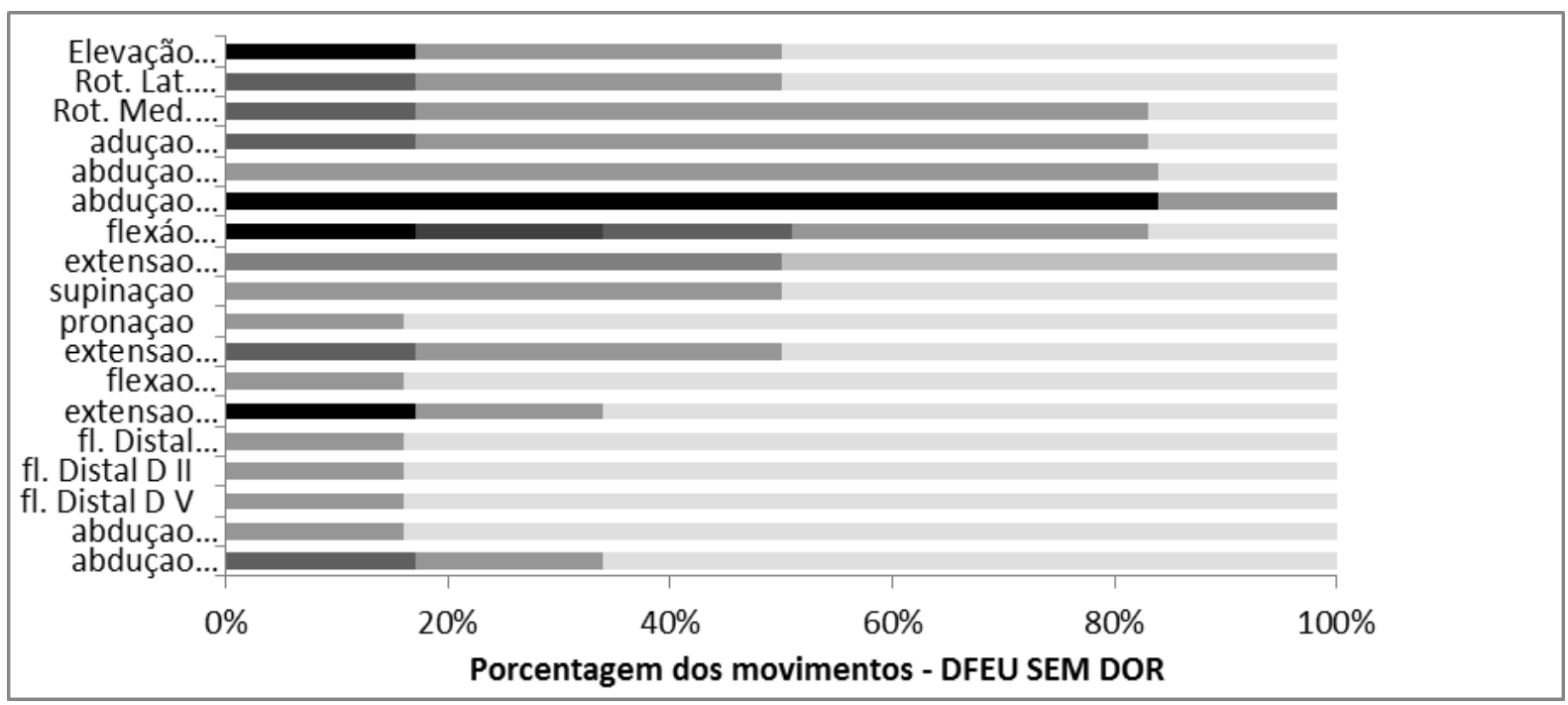

Gráfico 3.2: Distribuição de força em membros superiores nos pacientes sem dor 


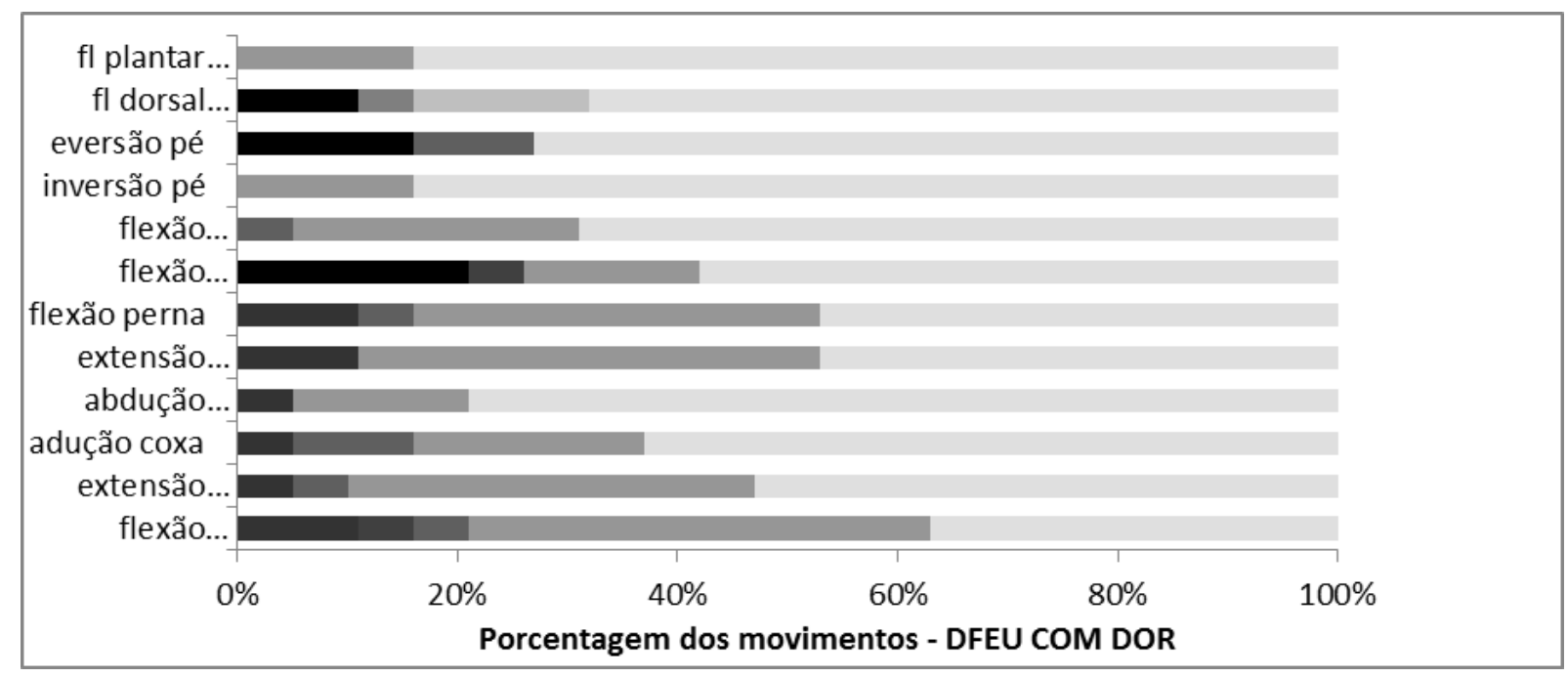

Gráfico 4.1: Distribuição de força em membros inferiores nos pacientes com dor

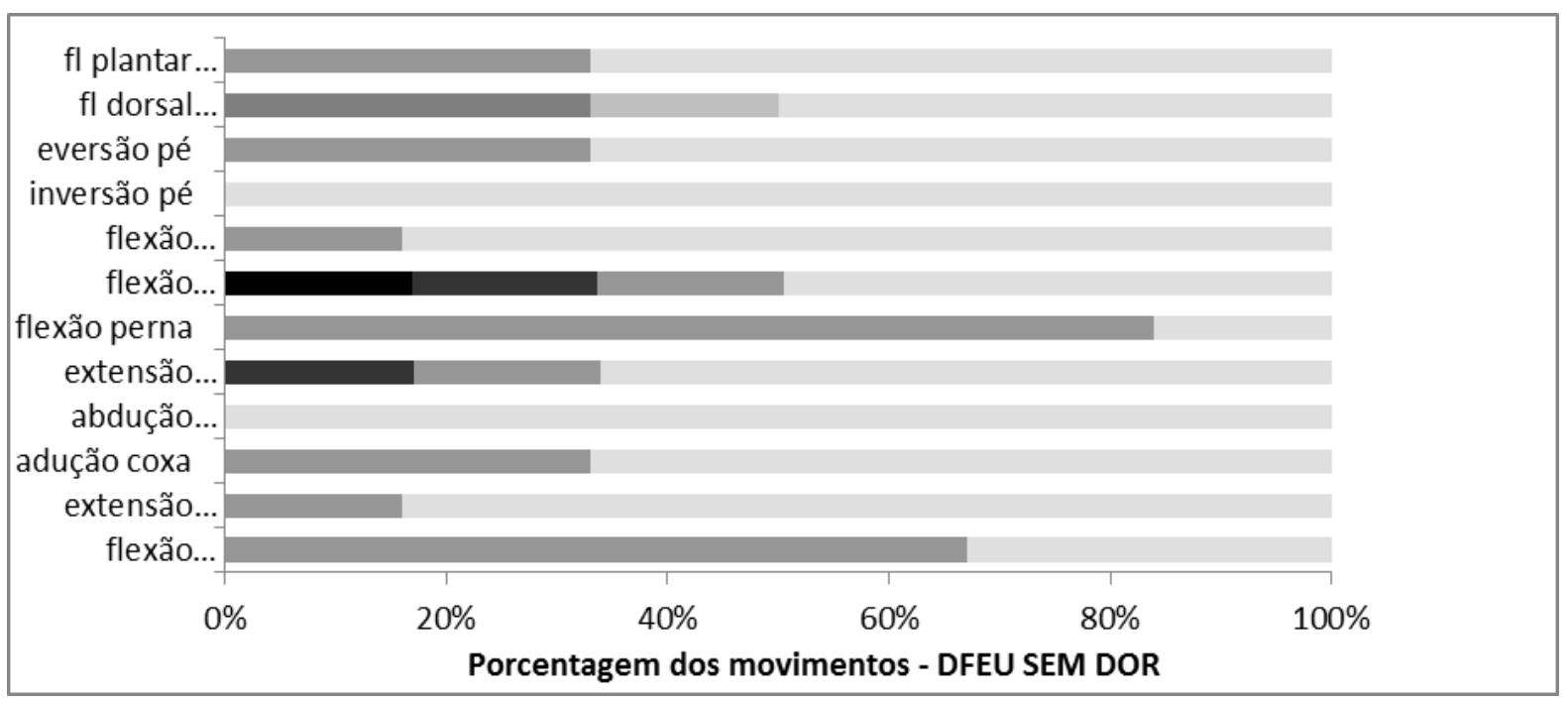

Gráfico 4.2: Distribuição de força em membros inferiores nos pacientes sem dor 
Em ambos os grupos, fica claro o acometimento predominante da musculatura proximal dos membros superiores. Já o acometimento dos membros inferiores não segue um padrão homogêneo.

Com relação à avaliação da força, medida pelo escore somado do MRC (cujo valor mínimo é 0 e o máximo é 60 ), não foi identificada diferença significativa entre os grupos de pacientes com DFEU com dor e sem dor (Tabela 2).

Tabela 2: Escore somado da MRC e dosagens de CK

\begin{tabular}{|c|c|c|c|c|c|}
\hline \multirow{2}{*}{} & \multicolumn{2}{|c|}{ DFEU com dor } & \multicolumn{2}{c|}{ DFEU sem dor } & p \\
\cline { 2 - 6 } & Média \pm DP & Variação & Média \pm DP & Variação & \\
\hline MRC (Escore somado) & $44,8 \pm 15,2$ & $4-60$ & $40,7 \pm 9,8$ & $28-56$ & 0,34 \\
\hline CK & & & & & \\
\hline Valor médio & $334,9 \pm 265$ & $95-698$ & $297,9 \pm 106,4$ & $267-463,3$ & 0,53 \\
\hline Menor valor & $273,4 \pm 277$ & $58,1-906,7$ & $223,5 \pm 57,9$ & $162-293$ & 0,34 \\
\hline Maior valor & $451,2 \pm 406,1$ & $95-1429$ & $375,1 \pm 202,7$ & $167-711$ & 0,67 \\
\hline
\end{tabular}

MRC: Medical Research Councill CK: Creatinaquinase sérica/ DP: Desvio padrão

Foram avaliados os níveis de creatinaquinase sérica (CK) de todos os pacientes. Dentro de cada subgrupo, foram avaliados valores médios, mínimos e máximos de CK (tabela 2). Não foram observadas grandes flutuações dos valores dessa enzima em nenhum dos dois grupos avaliados. Embora aparentemente os maiores valores de CK tenham sido observados no grupo de DFEU com dor, análise estatística não demonstrou diferença significativa entre os grupos. Cinco pacientes, sendo quatro pertencentes ao grupo com dor e um ao grupo sem dor, apresentaram valores de CK sempre dentro da normalidade.

Foi realizada uma revisão do padrão histológico desses pacientes. No grupo com dor, seis pacientes realizaram biópsia de músculo durante a investigação diagnóstica. Em duas delas foram encontrados achados distróficos. Uma das biópsias revelou achados sugestivos de disfunção mitocondrial. As outras duas revelaram alterações inespecíficas. No grupo sem dor, apenas um paciente realizou biópsia de músculo, que revelou achados distróficos. 
Foi avaliado o padrão eletrofisiológico desses pacientes. Um total de 12 pacientes realizou eletroneuromiografia durante o seguimento, sendo oito pacientes do grupo com dor e quatro pacientes do grupo sem dor. No grupo com dor, $75 \%$ dos pacientes apresentaram alterações miopáticas, 12,5\% alterações neurogênicas e $12,5 \%$ achados mistos. No grupo sem dor, 100\% dos pacientes apresentaram alterações miopáticas ao exame (gráfico 5).

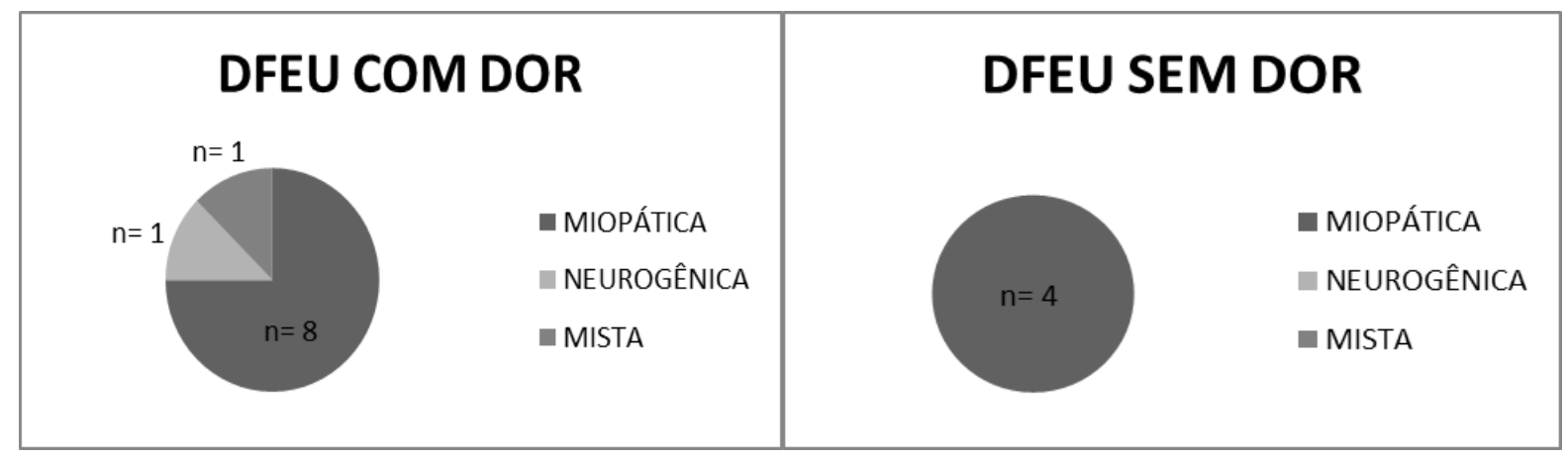

Gráfico 5: Achados eletroneuromiográficos dos pacientes com diagnóstico de DFEU com dor e sem dor

A tabela 3 apresenta os resultados com relação à presença de transtorno depressivo e de ansiedade

Tabela 3: Presença de Depressão e Ansiedade

\begin{tabular}{|c|c|c|}
\hline & $\begin{array}{c}\text { DFEU COM DOR } \\
\mathbf{n}(\%)\end{array}$ & $\begin{array}{c}\text { DFEU SEM DOR } \\
\mathbf{n}(\%)\end{array}$ \\
\hline DEPRESSÃO & \multicolumn{2}{|c|}{} \\
\hline SIM & $9(47,4 \%)$ & $4(66,7 \%)$ \\
\hline NÃO & $10(52,5 \%)$ & $5(83,3 \%)$ \\
\hline ANSIEDADE & \multicolumn{2}{|c|}{} \\
\hline SIM & $14(73,6 \%)$ & $1(16,7 \%)$ \\
\hline NÃO & $5(26,4 \%)$ & \\
\hline
\end{tabular}


Constatou-se que a depressão foi mais prevalente no grupo de pacientes com dor e a ansiedade parece ter atingido de forma semelhante os grupos com e sem dor. Entretanto, a análise realizada não mostrou diferença significativa dessas variáveis nos grupos $(p=0,67$ para variável depressão; $p=1,0$ para variável ansiedade). Não houve diferença na presença das variáveis depressão e ansiedade entre os sexos.

Foram aplicadas ferramentas para avaliação de fadiga e incapacidades nos dois grupos de pacientes (tabela 4). Embora a pontuação pela escala de gravidade da fadiga (FSS) fosse maior para os pacientes com dor, não se pôde estabelecer uma relação direta significativa entre fadiga e dor $(p=0,3899)$. Na avaliação de incapacidades, foram utilizadas as escalas de Brooke, escala de Vignos e índice de Barthel modificado. Através da escala de Brooke, observa-se baixo grau de incapacidade relacionada aos membros superiores em ambos os grupos, sem diferença significativa entre os grupos $(p=0,4033)$. Com relação às incapacidades avaliadas pela escala de Vignos, observam-se pacientes com graus maiores de incapacidade, também sem diferença significativa entre os grupos $(p=0,6827)$. $O$ índice de Barthel modificado evidenciou pacientes com alto grau de incapacidade, entretanto sem diferença significativa entre os grupos $(p=0,7258)$. Portanto, não foi possível associar a presença de dor à piora das incapacidades. Os intervalos possíveis e encontrados de cada ferramenta utilizada foram detalhados na tabela 4.

Tabela 4: Intensidade de fadiga e grau de incapacidade nos grupos

\begin{tabular}{|c|c|c|c|c|c|c|c|}
\hline & \multicolumn{3}{|c|}{ DFEU COM DOR } & \multicolumn{4}{|c|}{ DFEU SEM DOR } \\
\hline & $\begin{array}{c}\text { Média } \\
\text { (DP) }\end{array}$ & $\begin{array}{l}\text { Intervalo } \\
\text { possível }\end{array}$ & $\begin{array}{c}\text { Intervalo } \\
\text { encontrado }\end{array}$ & $\begin{array}{l}\text { Média } \\
\text { (DP) }\end{array}$ & $\begin{array}{l}\text { Intervalo } \\
\text { possível }\end{array}$ & $\begin{array}{c}\text { Intervalo } \\
\text { encontrado }\end{array}$ & $p$ \\
\hline FSS & $\begin{array}{l}43,73 \\
(14,4)\end{array}$ & 9- 63 & $15-62$ & $\begin{array}{l}36,16 \\
(19,1)\end{array}$ & $9-63$ & $9-52$ & 0,3899 \\
\hline BROOKE & $\begin{array}{c}2,26 \\
(1,04)\end{array}$ & $1-6$ & $1-4$ & $\begin{array}{c}2,66 \\
(1,03)\end{array}$ & $1-6$ & $1-4$ & 0,4033 \\
\hline VIGNOS & $\begin{array}{l}3,68 \\
(3,03)\end{array}$ & $1-10$ & $1-10$ & $\begin{array}{c}3 \\
(3,09)\end{array}$ & $1-10$ & $1-9$ & 0,6827 \\
\hline IBM & $\begin{array}{l}43,84 \\
(9,65)\end{array}$ & $10-50$ & $14-50$ & $\begin{array}{c}45 \\
(8,14)\end{array}$ & $10-50$ & $31-50$ & 0,7258 \\
\hline
\end{tabular}

DFEU: Distrofia facioescapuloumeral; DP: Desvio padrão; FSS: Escala de gravidade da fadiga; IBM: Índice de Barthel Modificado. 
Foram utilizadas ferramentas específicas para avaliação da dor no grupo de pacientes que apresentavam essa queixa, sendo os resultados apresentados na tabela 5 .

Tabela 5: Quantificação da dor, da catastrofização e da sua interferência na qualidade de vida.

\begin{tabular}{|c|c|c|c|c|c|}
\hline & Média (DP) & $\begin{array}{l}\text { Intervalo } \\
\text { possível }\end{array}$ & $\begin{array}{c}\text { Intervalo } \\
\text { encontrado }\end{array}$ \\
\hline \multicolumn{3}{|c|}{ ENID (11 PONTOS) } & $4(3,33)$ & $0-10$ & $0-10$ \\
\hline \multicolumn{3}{|l|}{ PCS } & $11,63(9,69)$ & $0-52$ & $0-34$ \\
\hline \multirow{5}{*}{$\begin{array}{l}\text { BPI } \\
\text { DOR }\end{array}$} & \multicolumn{2}{|c|}{ Dor mais forte } & $8,05(2,17)$ & $0-10$ & $2-10$ \\
\hline & \multicolumn{2}{|c|}{ Dor mais fraca } & $0,89(1,1)$ & $0-10$ & $0-3$ \\
\hline & \multicolumn{2}{|c|}{ Dor média } & $4,63(2,03)$ & $0-10$ & $1-8$ \\
\hline & \multicolumn{2}{|c|}{ Dor agora } & $3,36(3,45)$ & $0-10$ & $0-10$ \\
\hline & \multicolumn{2}{|l|}{ Total } & $16,94(6,42)$ & $0-40$ & $3-27$ \\
\hline \multirow{8}{*}{\multicolumn{2}{|c|}{$\begin{array}{c}\text { BPI } \\
\text { INTERFERÊNCIA }\end{array}$}} & Atividades & $6,73(2,94)$ & $0-10$ & $1-10$ \\
\hline & & Humor & $5,47(3,54)$ & $0-10$ & $0-10$ \\
\hline & & Marcha & $4,57(4,69)$ & $0-10$ & $0-10$ \\
\hline & & Trabalho & $6,84(3,86)$ & $0-10$ & $0-10$ \\
\hline & & Relacionamentos & $1,31(2,56)$ & $0-10$ & $0-9$ \\
\hline & & Sono & $3,89(4,28)$ & $0-10$ & $0-10$ \\
\hline & & Prazer de viver & $1,94(2,91)$ & $0-10$ & $0-10$ \\
\hline & & Total & $30,52(15,9)$ & $0-70$ & $1-54$ \\
\hline
\end{tabular}

ENID: Escala numérica de intensidade de dor/ PCS: Escala de pensamentos catastróficos/ BPI: Brief Pain Inventory/ DP: Desvio padrão 
A intensidade da dor avaliada pela ENID referiu-se à dor apresentada no momento da avaliação. Observamos que a dor não é constante nos pacientes com DFEU, pois quatro pacientes não apresentavam dor naquele momento (escore 0 ), embora houvesse um paciente que pontuou no escore mais alto da escala. A intensidade da dor pela ENID, no entanto, foi em média moderada. Já os escores obtidos para a escala de pensamentos catastróficos associados à dor foram proporcionalmente mais baixos, sendo que nenhum paciente pontuou no escore mais elevado possível da escala.

O BPI-B divide-se em duas abordagens. Na primeira, que avalia a intensidade da dor, podemos observar que os escores apresentados para a dor agora foram semelhantes aos obtidos pela ENID $(r=0,83 ; p<0,001)$, havendo seis pacientes que se apresentavam sem dor no momento da avaliação e um paciente que apresentou o escore máximo possível. A dor mais forte sentida nos últimos 3 meses foi em média bem elevada, embora um paciente tenha pontuado 2 , que é um valor baixo de intensidade de dor. A média de dor mais fraca foi baixa, indicando haver grande flutuação da intensidade da dor na DFEU. O somatório das intensidades de dor avaliadas por essa ferramenta apresentou um valor médio de 16,94, que representa um valor moderado.

Com relação aos locais de dor mais intensa, a topografia mais citada foi a lombar (referida por 11 pacientes), seguida de ombros (relatada por seis pacientes) e região escapular (mencionada por cinco pacientes). Vale ressaltar que todos os pacientes apontaram mais de uma região como sítio de dor.

Foi investigado sobre o tratamento utilizado para as dores referidas por esses pacientes. Dos 19 pacientes avaliados, quatro relataram não fazer uso de medicações. Três pacientes relataram necessidade de analgesia endovenosa. Os outros 12 pacientes fazem uso de analgésicos comuns, anti-inflamatórios e relaxantes musculares. Dos que fizeram uso de medicação, a média de alívio percentual de dor foi de $71 \%$. Tais achados sugerem que a dor apresenta taxa de alívio elevada, sem necessidade de analgésicos mais potentes ou medicações específicas.

Na segunda parte do BPI é avaliada a interferência da dor em vários aspectos da vida do paciente. Com relação à interferência nas atividades, observamos maior interferência nas atividades em geral, incluindo o trabalho, e no humor, e menor interferência nos relacionamentos e no prazer de viver. Há influência moderada da 
dor na capacidade da marcha e no sono (tabela 5).

No grupo de pacientes com dor, 12 relataram a dor como a maior limitação atual associada à sua doença. Desses, seis citaram a dor como único e maior fator limitante, enquanto que seis a consideraram o maior fator limitante em associação com a fraqueza muscular.

Dos seis pacientes sem dor, um paciente relata antecedente de dores intensas e incapacitantes, que reverteram com uso de salbutamol. Verificou-se ainda que um paciente está em uso atual de salbutamol e outro paciente fez uso prévio dessa medicação, mas ambos não recordam sobre presença de dor previamente à introdução dessa droga. No grupo de pacientes sem dor, a fraqueza foi considerada por todos os seis pacientes como o maior fator limitante associado à doença.

Foram realizados vários testes para avaliar a ocorrência de associação entre as ferramentas que avaliam dor, características demográficas e clínicas dos pacientes.

Foi constatado que a idade de início dos sintomas apresentou correlação muito alta com a idade no diagnóstico $(r=0,82 ; p<0,001)$.

A intensidade da dor e a interferência desta nas atividades de vida diária, ambas avaliadas pelo BPI, apresentaram uma relação direta moderada $(r=0,41 ; p=$ $0,08)$. Foi constatada ainda uma relação direta muito alta entre a intensidade da dor avaliada pelo BPI e pela ENID ( $r=0,83 ; p<0,001$ ). Não foi observada correlação da intensidade da dor com nenhum outro parâmetro avaliado.

O escore somado do MRC apresentou uma correlação negativa moderada com a interferência nas atividades de vida diária avaliada através do BPI ( $r=-0,42$; $p=0,07)$ e com a escala de Brooke $(r=-0,58 ; p=0,02)$, e alta correlação, também negativa, com a escala de Vignos $(r=-0,75 ; p<0,001)$. O escore somado do MRC apresentou uma alta correlação direta com o IBM $(r=0,67 ; p<0,001)$.

O IBM apresentou correlação negativa e elevada (alta e muito alta) com as escalas de Brooke $(r=-0,69 ; p<0,001)$ e Vignos $(r=-0,90 ; p<0,001)$.

As pontuações nas escalas de Brooke e Vignos apresentaram alta correlação direta $(r=0,70 ; p<0,001)$.

Foi encontrada uma relação direta e leve ou moderada da interferência da dor nas atividades de vida avaliada através do BPI com as escalas de Vignos $(r=0,40$; 
$p=0,09)$ e PCS $(r=0,46 ; p=0,07)$.

A interferência nas atividades de vida diária avaliada através do BPI apresentou correlação direta e elevada com a idade de início dos sintomas $(r=0,69$; $p=0,001)$, a idade no diagnóstico de DFEU $(r=0,68 ; p=0,001)$ e a idade do paciente na avaliação $(r=0,76 ; p<0,01)$.

A avaliação da fadiga pela FSS apresentou correlação direta e moderada com as escalas PCS $(r=0,57 ; p=0,01)$, Brooke $(r=0,42 ; p=0,04)$ e Vignos $(r=0,46 ; p=$ $0,02)$. 


\section{DISCUSSÃO}

A casuística incluída no estudo foi constituída por pacientes com quadro clínico de DFEU e com confirmação diagnóstica por estudo molecular em aproximadamente metade dos pacientes. Embora a situação ideal fosse a confirmação molecular na totalidade dos casos, a apresentação clínica é de certa forma específica quando considerados a distribuição do envolvimento muscular e o padrão de herança autossômico dominante (RICCl, 2013).

Os achados do presente estudo demonstraram que a dor é um sintoma clínico relevante na DFEU. Na nossa casuística, a prevalência de dor foi de $76 \%$, corroborando os achados de publicações anteriores (JENSEN, 2005; JENSEN, 2008). Já é bem estabelecido na literatura que a dor é um sintoma clínico prevalente nas desordens neuromusculares em geral. Estudos mais específicos foram realizados e revelaram uma maior prevalência de dor na DFEU em comparação a outras formas de distrofia, como a distrofia miotônica (JENSEN, 2008).

Foi constatada uma predominância de sexo feminino no grupo de pacientes com dor. Tal achado vai ao encontro das publicações já existentes, que descreveram predominância de $57 \%$ de mulheres portadoras de DFEU e que cursavam com dor (NIETO, 2012).

A idade na avaliação não diferiu entre os grupos de pacientes com dor e sem dor. A intensidade da dor não apresentou associação direta com a idade. Tal achado já foi descrito em publicação anterior (JENSEN, 2008).

Os demais dados demográficos pesquisados (idade de início dos sintomas, tempo de evolução da doença e escolaridade) não apresentaram associação com presença de dor. Também não há relatos na literatura de que esses dados possam estar relacionados à dor.

O fenômeno da antecipação esteve presente de forma expressiva em ambos os grupos, o que já é bem definido como característica dessa doença (ROLAND, 1998; BROOKE, 1999). Não houve diferença na ocorrência desse fenômeno em ambos os grupos, não havendo, portanto, associação entre antecipação e dor.

A maior parte dos pacientes avaliados pertencia à primeira ou segunda geração acometida na família, tanto no grupo com dor como no grupo sem dor, portanto, não há como associar esses achados à ocorrência de dor.

Foi realizada uma descrição fenotípica da amostra de acordo com a 
classificação proposta mais recentemente (RICCl, 2016). Essa classificação não está associada à gravidade de doença e, portanto, não há como relacioná-la com dor ou outros achados clínicos. Como a amostra é pequena, não foi possível delinear o perfil fenotípico com fidelidade, tendo em vista que a classificação descreve nove fenótipos possíveis e na nossa casuística só foram constatados quatro desses fenótipos.

Com relação à força avaliada pelo escore somado do MRC, não foi observada diferença significativa entre os grupos de pacientes, ou seja, não houve relação entre presença de dor e maior comprometimento de força. Os níveis séricos de CK foram semelhantes em ambos os grupos, mostrando que também não houve associação entre presença de dor e grau de lesão muscular. Tais achados foram de encontro ao esperado, visto que uma explicação plausível para a alta prevalência de dor na DFEU seria a de que os pacientes mais fracos apresentariam maior grau de lesão muscular por necrose, maior grau de atrofia por desuso e maior limitação funcional e que essas alterações poderiam influenciar na gênese de dor. Uma teoria semelhante já havia sido sugerida em estudo prévio (JENSEN, 2008), contudo também não pode ser comprovada pelos resultados encontrados.

O padrão de fraqueza de distribuição proximal, com acometimento preferencial da musculatura facioescapuloumeral foi claramente demonstrado no gráfico 3, refletindo a descrição clássica da doença (FELIZE, 2000; KRASNIANSKI, 2003). O gráfico 4 mostrou acometimento de membros inferiores, corroborando os relatos da literatura de que esses grupos musculares também são acometidos com a evolução da doença (VAN DER KOOI, 2000).

Durante a investigação diagnóstica, sete pacientes realizaram biópsia de músculo. Três biópsias apresentaram achados distróficos, conforme esperado para essa doença, duas biópsias apresentaram achados inespecíficos e uma biópsia revelou achados de disfunção mitocondrial. Os achados inespecíficos podem ser decorrentes do sítio escolhido para biópsia não estar tão acometido pela doença, já que a DFEU acomete a musculatura de forma assimétrica. Já os achados indicativos de disfunção mitocondrial podem representar alterações secundárias ao processo crônico degenerativo.

A avaliação do padrão eletrofisiológico revelou que doze pacientes realizaram eletroneuromiografia. Apesar do restrito número de pacientes no grupo com DFEU sem dor, chama a atenção o fato de que alterações neurogênicas só foram 
observadas nos pacientes com dor. A única paciente com alterações mistas recebeu, ao longo do acompanhamento clínico, diagnóstico de radiculopatia cervical associada, o que pode ter piorado o quadro álgico existente previamente a esse diagnóstico.

O diagnóstico de ansiedade e depressão como comorbidades associadas à DFEU foi bastante prevalente, especialmente a ansiedade. Entretanto, essas doenças não apresentam correlação com a dor, sendo provavelmente associadas à desordem neuromuscular em si. Alguns estudos avaliaram a presença de depressão como comorbidade da DFEU através de outras ferramentas e os resultados sugerem achados semelhantes ao do presente trabalho (PADUA, 2009).

A literatura mostra que a presença de dor está associada à piora da fadiga (KALKMAN, 2005; STANOS, 2006). Na nossa casuística, apesar da pontuação média da escala que avaliou gravidade da fadiga ter sido maior no grupo com dor do que no grupo sem dor, não foi demonstrada diferença estatística entre os grupos. Portanto, não foi possível associar dor à gravidade da fadiga.

A gravidade da fadiga esteve diretamente relacionada à piora de incapacidades e tal achado já foi demonstrado em publicações prévias (KALKMAN, 2005; STANOS, 2006).

$\mathrm{Na}$ avaliação de incapacidades, não houve diferença significativa entre os valores médios das escalas de Brooke, Vignos e IBM. Portanto, não foi possível associar a presença de dor ao grau de incapacidade física.

No grupo sem dor, um paciente relatou apresentar dores intensas e incapacitantes que reverteram com uso de salbutamol. Um paciente estava em uso de salbutamol na ocasião da avaliação e outro paciente havia feito uso anterior dessa droga, contudo ambos não conseguem associar temporalmente o uso desse fármaco com o desaparecimento da dor. $O$ uso de agonistas beta-adrenérgicos como albuterol e salbutamol já foi motivo de estudos prévios. A explicação para esse fato seria a de que o efeito mio relaxante dessa medicação poderia influenciar positivamente a força e o volume muscular em pacientes com DFEU, atuando assim de forma positiva sobre a dor e a fadiga. Um estudo duplo-cego controlado foi realizado com uso de albuterol de liberação prolongada, associado a treinamento de força em músculos específicos (flexores do cotovelo e dorsiflexores do tornozelo). Entretanto os resultados mostraram que treinamento de força e albuterol não apresentaram efeito positivo ou negativo sobre a dor na DFEU (VAN DER KOOI, 
2007).

A intensidade média da dor encontrada no presente trabalho foi categorizada como moderada e esteve de acordo com o que é descrito na literatura (JENSEN, 2008; NIETO, 2012).

Já é bem estabelecida na literatura uma relação direta entre intensidade da dor e PCS (NIETO, 2012). Entretanto, não foi possível demonstrar essa associação na nossa casuística. No presente estudo, constatou-se apenas que a PCS possui relação direta com a interferência da dor na qualidade de vida avaliada pelo BPI e que essa última apresenta correlação direta com a intensidade da dor avaliada pelo BPI. Essa correlação direta entre intensidade da dor e interferência da dor na qualidade de vida, ambas avaliadas pelo BPI, corrobora os dados já publicados previamente (JENSEN, 2008).

As topografias relatadas como alvo de dores mais intensas no nosso estudo foram ombros, região cervical, região periescapular e região lombar. Relatos prévios apontam os membros inferiores como a região mais acometida por dor na DFEU (JENSEN, 2008).

Com relação ao tratamento da dor, a taxa de uso de medicações para alívio desse sintoma foi elevada. As drogas mais citadas pelos pacientes foram analgésicos, anti-inflamatórios e relaxantes musculares, reafirmando o que havia sido descrito em outros trabalhos (JENSEN, 2008). A taxa de alívio da dor no presente trabalho foi de $71 \%$ e não há relatos na literatura para comparação.

Existem perspectivas de desenvolvimento de novas modalidades farmacológicas e terapia gênica, que levariam ao crescimento da massa muscular e consequente melhora funcional desses músculos, o que poderia ajudar no manejo da dor (JENSEN, 2008).

Confirmando os achados do estudo preliminar realizado nesse serviço (CRUZ, 2014), a presença de dor nos pacientes com DFEU acarreta interferências significativas nas atividades de vida diária, quando avaliados os quesitos atividades em geral, humor, capacidade de andar, trabalho, relacionamentos, sono e prazer de viver. 


\section{CONCLUSÕES}

Os achados do presente estudo revelaram que a dor é um sintoma relevante na DFEU, de caráter predominantemente focal e mais prevalente no sexo feminino. Há uma clara interferência da dor nas atividades de vida diária, entretanto, esse sintoma não se correlaciona com os demais parâmetros clínicos e laboratoriais (tempo de evolução da doença, força muscular, grau de incapacidade física e valor da CK). 


\section{REFERENCIAS}

ARLINGTON, V. A.; "Diagnostic and Statistical Manual of Mental Disorders, Fifth Edition (DSM-V).”. American Psychiatric Association, (2013).

AJZEN, I.; "Understanding attitudes and predicting social behavior". New Jersey: Prentice-Hall, Inc., Englewood Cliffs, 1998.

BROOKE, M. H.; "A selective review of muscular dystrophies. Annual Educational Program of the American Academy of Neurology". Update on Neuromuscular diseases. Toronto: American Academy of Neurology, (1999).

BROOKE, M. H.; GRIGGS, R. C.; MENDELL, J. R.; FENICHEL, G. M.; SHUMATE, J. B.; PELLEGRINO, R. J.; "Clinical trial in Duchenne dystrophy: the design of the protocol”. Muscle nerve, 4(1981): 186-97.

BUSHBY, K. M. D.; et al. "Muscle pain as a proeminent feature of facioscapulohumeral muscular dystrophy (FSHD): four illustrative case reports". Neuromuscular Disorders, 8 (1998): 574-579.

CINCURA, C.; et al. "Validation of the national institutes of health stroke scale, modified ranking scale and Barthel index in Brazil: the role of cultural adaptation and structured interviewing". Cerebrovasc. Dis., New York, 27 (2) (2009): 119-122.

CRUZ, C. A.; "Pain in facioscapulohumeral dystrophy: severity and interference with daily activities". XXVI Congresso Brasileiro de Neurologia, (2014).

DAVIS, L. G.; DIBNER, M. D.; BATTEY, J. F.; "Methods in molecular biology". Elsevier, New York, (1986): 47-50.

DUCHENNE, G.; "Récherches sur la paralysie musculaire pseudohypertrophique, ou paralysie myosclérosique”. Arch Gén Méd, 11 (1868)

DUCHENNE, G.; Album de photographies pathologiques, (1862) 
EMERY, A. H.; "Population frequencies of inherited neuromuscular diseases: a world survey". Neuromuscul Disord, 1(1991): 19-25.

FELIZE, K. J.; NORTH, W. A.; et al. "FSH dystrophy $4 q 35$ deletion in patients presenting with facial-sparing scapular myopathy". Neurology, 54(10) (2000): 19271931.

FITZSIMONS, R. B.; GURWIN, E. B.; BIRD, A. C.; "Retinal vascular abnormalities in facioscapulohumeral muscular dystrophy. A general associtation with genetic and therapeutic implications". Brain, 110 (1987): 631-648.

GABELLINI, D.; GREEN, M. R.; TUPLER, R.; "Inappropriate gene activation in FSHD: A repressor complex binds a chromosomal repeat deleted in dystrophic muscle". Cell, 110 (2002): 339-348.

GOMES, L. R.; "Validação da versão portuguesa da Escala de Impacto da Fadiga Modificada e da Escala de Severidade da Fadiga na Esclerose Múltipla". Universidade do Minho, Braga, Portugal, (2011).

GOTO, K.; NISHINO, I.; HAYASHI, Y. K.; "Rapid and accurate diagnosis of facioscapulohumeral muscular dystrophy". Neurom Disord., 16 (2006): 256-261.

GUY-COICHARD, C.; NGUYEN, D. T.; DELORME, T.; BOUREAU, F.; "Pain in hereditary neuromuscular disorders and myasthenia gravis: a national survey of frequency, characteristics, and impact”. J Pain Symptom Manage, 35 (2008): 40-50.

JENSEN, M. J.; KAROLY, P.; BRAVER, S.; "The measurement of clinical pain: a comparison of six methods". Pain, 27 (1986): 117-126.

JENSEN, M. P.; TURNER, J. A.; ROMANO, J. M.; "What is the number of levels needed in pain intensity measurement?". Pain, 58(1994): 387-392. 
JENSEN, M. P.; ABRESCH, R. T.; CARTER, G. T.; "The reliability and validity of a self-reported version of the FIM in persons with neuromuscular disease and chronic pain”. Arch Phys Med Rehabil, 86 (2005): 116-122.

JenSEN, M. P.; HOFFMAN, A. J.; STOELB, B. L.; ABRESCH, R. T.; CARTER, G. T.; McDONALD, C. M.; "Chronic Pain in Persons With Myotonic Dystrophy and Facioscapulohumeral Dystrophy”. Arch Phys Med Rehabil, 89 (2008): 320-328.

JUNIOR, J. S.; NICHOLAS, M. K.; PEREIRA, O. A.; PIMENTA, C. A. M.; ASGHARI, A.; CRUZ, R. M.; "Validação da Escala de Pensamentos Catastróficos sobre Dor". Acta Fisiátr, 15 (1) (2008): 31-36.

KALKMAN, J. S.; SCHILLINGS, M. L.; VAN DER VERF, S. P.; "Experienced fatigue in Facioscapulohumeral dystrophy, myotonic dystrophy, and HMSN-l". J Neurol Neurosurg Psychiatry, 76 (2005): 1406-1409.

KILMER, D. D.; ABRESCH, R. T.; McCRORY, M. A.; "Profiles of neuromuscular diseases. Facioscapulohumeral muscular dystrophy”. Am J Phys Med Rehabil, 74 (1995): S131-S145.

KLEYWEG, R. P.; VANDERMECHE, F. G. A.; SCHIMITZ, P. I. M.; "Interobserver agreement in the assessment of muscle strength and functional abilities in GuillainBarré syndrome”. Muscle \& Nerve, 14 (11) (1991): 1103-1109.

KRASNIANSKI, M.; EGER, K.; NEUDECKER, S.; JAKIBICZKA, S. ZIERZ, S.; "Atypical phenotypes in patients with facioscapulohumeral muscular dystrophy $4 q 35$ deletion". Acrh Neurol, 60 (2003): 1421-5.

LAMPERTI, C.; FABBRI, G.; VERCELLI, L.; D'AMICO, R.; FRUSCIANTE, R.; BONIFAZI, E.; FIORILLO, C.; BORSATO, C.; CAO, M.; SERVIDA, M. et al. "A standardized clinical evaluation of patients affected by facioscapulohumeral muscular dystrophy: The FSHD clinical score". Muscle Nerve, 42(2010): 213-217. 
LANDOUZY, L.; DEJERINE, J.; "De la myopathie atrophique progressive". Rev Med Francaise, 5 (1885): 81.

LEMMERS, R. J. L. F.; et al. "Best practice guidelines on genetic diagnostics of Facioscapulohumeral muscular dystrophy: Workshop $9^{\text {th }}$ June 2010 , LUMC, Leiden, The Netherlands". Neurom Disord, 22 (2012): 463-470.

MIRÓ, J.; GERTZ, K. J.; CARTER, G. T.; JENSEN, M. P.; "Pain location and intensity impacts function in persons with myotonic dystrophy type 1 and facioscapulohumeral dystrophy with chronic pain". Muscle Nerve, 49 (2014): 900-5.

MIRÓ, J.; RAICHLE, K. A.; CARTER, G. T.; O'BRIEN S. A.; ABRESCH R. T.; McDONALD C. M.; JENSEN, M. P.; "Impact of biopsychosocial factors on chronic pain in persons with myotonic and facioscapulohumeral muscular dystrophy". Am $\mathbf{J}$ Hosp Palliat Care, 26 (2009): 308-19.

NIETO, R.; RAICHLE, K. A.; JENSEN, M. P.; MIRO, J.; "Changes in pain-related beliefs, coping, and Catastrophizing predict changes in pain intensity, pain interference, and psychological functioning in individuals with Myotonic Muscular Dystrophy and Facioscapulohumeral Dystrophy". Clin J Pain, 28 (2012): 47-54.

NIKOLIC, A.; RICCI, G.; SERA, F.; et al. "Clinical expression of facioscapulohumeral muscular dystrophy in carriers of 1-3 D4Z4 reduced alleles: experience of the FSHD Italian National Registry". BMJ Open, 6(1)(2016): e007798.

PADBERG, G. W.; BROUWER, O. F.; KEIXER, R. J.; "On the significance of retinal vascular disease and hearing loss in facioscapulohumeral dystrophy". Muscle Nerve, 2 (1995): S73-S78.

PADUA, L.; APRILE, I.; FRUSCIANTE, R.; IANNACCONE, E.; ROSSI, M.; RENNA, R.; MESSINA, S.; FRASCA, G.; RICCI, E.; "Quality of life and pain in patients with facioscapulohumeral muscular dystrophy”. Muscle Nerve, 40 (2009): 200-205.

PEARSON. "Two new pedigrees of muscular dystrophy". Ann Eugen, 5 (1933):179191. 
PERSONIUS, K. E.; PANDYA, S.; et al. "Facioscapulohumeral dystrophy natural history study: Standartization of testing procedures and reliability of measurements". The FSH DY Group. Phys Ther, 74 (3) (1994): 253-263.

RICCI, G.; RUGGIERO, L.; VERCELLI, L.; SERA, F.; NIKOLIC, A.; GOVI, M.; MELE, F.; DAOLIO, J.; ANGELINE, C.; ANTONINI, G.; BERARDINELLI, A.; BUCCI, E.; CAO, M.; D’AMICO, M. C.; D’ANGELO, G.; MUZIO, A, D.; FILOSTO, M.; MAGGI, L.; MOGGIO, M.; MONGINI, T.; MORANDI, L.; PEGORARO, E.; RODOLICO, C.; SANTORO, L.; SICILIANO, G.; TOMELLERI, G.; VILLA, L.; TUPLER, R.; "A novel clinical tool to classify facioscapulohumeral muscular dystrophy phenotypes". J Neurol., 263(6) (2016): 1204-14.

RICCI, G.; SCIONTI, I.; SERA, F.; et al. "Large scale genotypephenotype analyses indicate that novel prognostic tools are required for families with facioscapulohumeral muscular dystrophy". Brain, 136 (2013): 3408-3417.

RICCI, G.; ZATZ, M.; TUPLER, R.; "Facioscapulohumeral muscular dystrophy: more complex than it appears". Curr Mol Med, 14 (2014):1052-1068.

ROLAND, L. P.; "Molecular basis of genetic heterogenety: role of the clinical neurologist". J Child Neurol, 13 (1998): 122-32

SEHN, F. C.; "Validação da escala de pensamentos catastróficos e associação do catastrofismo com marcadores biológicos". Dissertação de mestrado pela Universidade Federal do Rio Grande do Sul. Porto Alegre, RS, (2012).

SEHN, F. C.; "Association of catastrophyzing with TNF and cortisol in cronic tension headace". Pos-graduation Program in Medical Science, Universidade Federal do Rio Grande do Sul. Porto Alegre, (2012).

SHAH, S.; VANCLAY, F.; \& COOPER, B.; "Improving the sensitivity of the Barthel Index for stroke rehabilitation”. Journal of Clinical Epidemiology, 42 (1989a): 703 709. 
SILVA, M. B.; ASA, S. K. P.; MANIA, N. N. S.; ZANELA, E. M.; FAVERO, F. M.; FUKUJIMA, M. M.; FONTES, S. V.; OLIVEIRA, A. S. B.; "Clinical assessments analysis of myopathy". Rev Neurocienc, 14 (2006): 029-043.

SMITH, A. E.; McMULLEN, K.; JENSEN, M. P.; CARTER, G. T.; MOLTON, I. R.; "Symptom burden in persons with myotonic and facioscapulohumeral muscular dystrophy". Am J Phys Med Rehabil, 93 (2014): 387-95.

SteVEnSON, W. G.; PERLOFF, J. N.; WEISS, J. N.; ANDERSON, T. L.; "Facioscapulohumeral muscular dystrophy: evidence for selective, genetic electrophysiologic cardiac involvement”. J Am Coll Cardiol, 15 (1990): 292-299.

STANOS, S.; HOULE, T. T.; "Multidisciplinary and interdisciplinary management of chronic pain". Phys Med Rehabil Clin N Am, 17 (2006): 435-450.

TAWILL, R.; "Facioscapulohumeral muscular dystrophy". Curr Neurol Neurosci Rep, 4 (1) (2004): 51-54.

TAWILL, R.; VAN DER MAAREL, S. M.; "Facioscapulohumeral muscular dystrophy". Muscle Nerve, 34 (1) (2006):1-15.

TOLEDO, F. O.; "Adaptação cultural do inventário breve da dor para a língua portuguesa no Brasil e o teste de suas propriedades psicométricas". Dissertação (Mestrado). Departamento de Neurociências e Ciências do Comportamento, Faculdade de Medicina de Ribeirão Preto, Brasil, 2008.

TOLEDO, F. O; "Validação do teste dinamométrico de contração voluntária máxima isotônica durante 5 minutos e identificação de fadiga patológica em pacientes com intolerância ao exercício físico". Dissertação (Doutorado). Departamento de Neurociências e Ciências do Comportamento, Faculdade de Medicina de Ribeirão Preto, Brasil, 2012. 
UPADHYAYA, M.; LUNT, P. W.; SARFARAZI, M.; et al. "DNA marker applicable do presymptomatic and prenatal diagnosis of facioscapulohumeral disease". Lancet, 336(1990): 1320-1321.

VAN DER KOOI, E. L.; VAN ENGELEN, B. G. M.; PADBERG, G. W.; "Effects of training and albuterol on pain and fatigue in Facioscapulohumeral muscular dystrophy". J Neurol, 254 (2007):931-940.

VAN DER KOOI, A. J.; VISSER, M. C.; et al. "Extension of the clinical range of facioscapulohumeral dystrophy: Report of six cases". J Neurol Neurosurgery Psychiatry, 69 (1) (2000): 114-116.

VIGNOS, P. J.; ARCHIBALD, K. C.; SPENCER, G.; "Management of progressive muscular dystrophy of childhood". JAMA, 184 (1963): 89-110.

WIJMENGA, C.; PADBERG, G. W.; MOERER, P; et al. "Mapping of facioscapulohumeral muscular dystrophy gene to chromosome $4 \mathrm{q} 35$-qter by multipoint linkage analysis and in situ hybridization". Genomics, 9 (1991) :570-575.

WIJMENGA, C.; HEWITT, J. E.; SANDKUIJL, L. A. et al. "Chromosome 4q DNA rearrangements associated with facioscapulohumeral muscular dystrophy". Nat Genet, 2 (1992): 26-30.

ZATZ, M.; MARIE, S. K.; PASSOS-BUENO, M. R.; VAINZOF, M.; CAMPIOTTO, S.; CERQUEIRA, A.; WIJMENGA, C.; PADBERG, G.; FRANTS, R.; "High Proportion of New Mutations and Possible Anticipation in Brazilian Facioscapulohumeral Muscular Dystrophy Families". Am.J. Hum. Genet, 56 (1995): 99-105. 


\section{ANEXOS}

\section{Aprovação Comitê de Ética}

Ribeirão Preto, 14 de abril de 2016

Oficio $n^{\circ} 1274 / 2016$

CEP/MGV

\section{Prezadas Senhoras,}

O trabalho intitulado "AVALIAÇÃo DA MIALGIA, FADIGA E CÄIBRA EM PACIENTES COM MIOPATIA", - versão 3, de 21/03/2016 foi analisado pelo Comitê de Ética em Pesquisa em sua $425^{\text {a }}$ Reunião Ordinária, realizada em 11/04/2016 e enquadrado na categoria: APROVADO, bem como o Termo de Consentimento Livre e Esclarecido - versão 3, de 21/03/2016, de acordo com o Processo HCRP n ${ }^{\circ} 15990 / 2015$.

De acordo com Carta Circular $n^{\circ} 003 / 2011 / C O N E P / C N S$, datada de 21/03/2011, o sujeito de pesquisa ou seu representante, quando for o caso, deverá rubricar todas as folhas do Termo de Consentimento Livre e Esclarecido TCLE - apondo sua assinatura na última do referido Termo; o pesquisador responsável deverá da mesma forma, rubricar todas as folhas do Termo de Consentimento Livre e Esclarecido - TCLE - apondo sua assinatura na última página do referido Termo.

Este Comitê segue integralmente a Conferência Internacional de Harmonizaçāo de Boas Práticas Clínicas (IGH-GCP), bem como a Resolução n 466/12 CNS/MS.

Lembramos que devem ser apresentados a este CEP; o Relatório Parcial e o Relatório Final da pesquisa.

Atenciosamente.

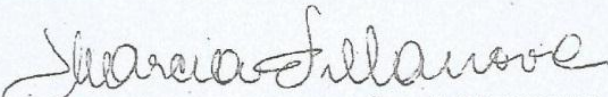

DR ${ }^{a}$. MARCIA GUIMARÃES VILLANOVA

Coordenadora do Comitê de Ética em Pesquisa do HCRP e da FMRP-USP

Ilustrissimas Senhoras

\section{KAROLINA DE BRITO BARBOSA TRINDADE}

PROF ${ }^{2} . D^{2}$.CLAUDIA FERREIRA DA ROSA SOBREIRA(Orientadora)

Depto. de Neurociências e Ciências do Comportamento

HOSPITAL DAS CLINICAS DA FACULDADE DE MEDICINA DE RIBEIRÃO PRETO DA UNNIVERSIDADE DE SĀO PAULO Campus Universitáric - Monte Alegre Comitê de Ética em Pasquitsa do HCRP e FMARP-USP 14048-900 Ribeirăo Preto SP FWA-00002733; IRB-00002186 e Registro PB/CONEP n० 5440 www.horp.usp.br (16)3602-2228/cep@hcrp.usp.br 


\section{Termo de Consentimento}

\section{TERMO DE CONSENTIMENTO LIVRE E ESCLARECIDO (GRUPO PACIENTE)}

Nome da pesquisa: Caracterização clínica da mialgia, fadiga e cãibra nos pacientes com miopatia.

\section{Pesquisadores responsáveis:}

Cláudia Ferreira da Rosa Sobreira

Karolina Brito Barbosa

Margleice Marinho Vieira Rocha

Convidamos o (a) Sr (a) para participar dessa Pesquisa. Sua participação é voluntária não havendo ajuda de custo por participar da pesquisa. Sua participação se dará em responder dois questionários, aplicados por uma fisioterapeuta ou médica neurologista, que fazem parte da pesquisa, enquanto aguarda sua consulta de rotina no nosso hospital. O primeiro questionário é sobre dor e o segundo sobre dor, fadiga e cãibra. Eles levam cerca de 10 minutos no total para serem respondidos. As miopatias são doenças que agridem os músculos. Como sintomas o paciente pode apresentar fraqueza no músculo, fadiga (cansaço) e dor muscular. A fadiga é a sensação de cansaço que vem junto com dor muscular depois de alguma atividade física, esse conjunto de sintomas é chamado de intolerância ao exercício. As cãibras são contrações musculares involuntárias, dolorosas e acontecem de repente, podendo durar de segundos a minutos. E para o tratamento adequado é necessário que esses sintomas sejam identificados corretamente. Os objetivos desta pesquisa são:

- Avaliar quantos pacientes com diagnóstico ou suspeita de miopatia que são acompanhados no Ambulatório de Doenças Neuromusculares do Hospital das Clínicas da Faculdade de Medicina de Ribeirão Preto da Universidade de São Paulo (ANEM/HCFMRP-USP) têm dor, fadiga e cãibra muscular;

- Avaliar sua dor muscular;

- Avaliar sua fadiga (cansaço);

- Avaliar sua cãibra;

- Avaliar a relação da dor, fadiga e cãibra com as alterações na sua doença;

Se o (a) $\mathrm{Sr}$ (a) aceitar participar, terá os seguintes direitos:

A) Se depois de consentir em sua participação o $\mathrm{Sr}$ (a) desistir de continuar participando, tem o direito e a liberdade de retirar seu consentimento em qualquer fase da pesquisa, seja antes ou depois da coleta dos dados, independente do motivo e sem nenhum prejuízo a sua pessoa.

B) $\mathrm{O}$ (a) $\mathrm{Sr}$ (a) não terá nenhuma despesa e também não receberá nenhum pagamento.

C) Sua identidade não será divulgada, sendo guardada em segredo.

VERSÃO 3. DATA DA MODIFICACÃO: 20-03-2016 
D) A garantia de receber a resposta a qualquer pergunta ou esclarecimento de qualquer dúvida a respeito dos procedimentos, riscos, benefícios e de outras situações relacionadas com a pesquisa em questão;

E) O compromisso de que será prestada qualquer informação durante o estudo, ainda que o (a) $\mathrm{Sr}$ (a) possa não querer mais participar do estudo;

F) O compromisso de que não haverá nenhum gasto para o (a) $\mathrm{Sr}$ (a) ou para sua família, decorrente de qualquer etapa desta pesquisa.

Para qualquer outra informação, o (a) $\mathrm{Sr}$ (a) poderá entrar em contato com os pesquisadores envolvidos pelos telefones (16) 3315-3312/3602-2548

Ribeirão Preto, de de

Participante:

RG:

Assinatura:

Ribeirão Preto, de de

Pesquisador:

Assinatura: 
FSHD Evaluation Scale

\section{I - Facial weakness}

0 - no weakness

1 - moderate weakness;

partial ability to do at least one of the following tasks:

- to close eyes

- to protrude lips

- to puff out cheeks

2 - severe weakness;

unable to do at least one of the following tasks:

- to close eyes

- to protrude lips

- to puff out cheeks

\section{II - Scapular girdle involvement}

0 - no involvement

1 - mild involvement with no limitation of arm abduction (patient can rise arms above head but only by flexing the elbow or using the accessory muscle)

2 - arm abduction $>45^{\circ}$ but $<180^{\circ}$

3 - arm abduction $\leq 45^{\circ}$

\section{III - Upper limbs involvement *}

0 - no involvement

1 - at least two muscles affected with $3<\mathrm{MRC} \leq 5$

2 - at least two muscles with $\mathrm{MRC} \leq 3$

*The following 4 muscles will be assessed on each side: 1.triceps; 2. biceps; 3 . common finger extensors and wrist extensors; 4. long finger flexors and wrist flexors.

Only the weaker muscles will be considered for evaluation.

\section{IV - Legs involvement}

The ability to walk on tiptoes and heels will be assessed on each side:

0 - no involvement

1 - unable to walk on tiptoes or heels (only one task impaired)

2 - unable to walk on tiptoes and heels (two tasks impaired)

\section{$\mathrm{V}$ - Pelvic girdle involvement}

0 - no involvement

1 - able to walk and to climb stairs without support but abnormally because of anterior leg muscle weakness

2 - able to walk unaided, to climb stairs or to stand up from a chair with support and/or tibialis anterior and quadriceps $3<\mathrm{MRC} \leq 5$

3 - able to walk unaided but unable to stand up from a chair or to climb stairs without support/more than 12 seconds and tibialis anterior and quadriceps $\mathrm{MRC} \leq 3$

4 - able to walk with support

5 - wheelchair bound

\section{VI - Abdominal muscle involvement}

0 - no involvement

1 - presence of Beevor's sign

\section{FSHD clinical score:}


FSS (Fatigue Severity Scale)

\begin{tabular}{|c|c|c|c|c|c|c|c|}
\hline $\begin{array}{l}\text { 1. A minha motivação } \\
\text { é menor quando } \\
\text { estou fatigado }\end{array}$ & $\begin{array}{l}\text { Discordo } \\
\text { inteiramente }\end{array}$ & 2 & 3 & 4 & 5 & 6 & $\begin{array}{l}\text { Concordo } \\
\text { inteiramente }\end{array}$ \\
\hline \multirow{2}{*}{$\begin{array}{l}\text { 2. O exercício físico } \\
\text { provoca-me fadiga. }\end{array}$} & $\begin{array}{l}\text { Discordo } \\
\text { inteiramente }\end{array}$ & & & & & & $\begin{array}{l}\text { Concordo } \\
\text { inteiramente }\end{array}$ \\
\hline & 1 & 2 & 3 & 4 & 5 & 6 & 7 \\
\hline \multirow{2}{*}{$\begin{array}{l}\text { 3. Eu fico fatigado } \\
\text { facilmente. }\end{array}$} & $\begin{array}{l}\text { Discordo } \\
\text { inteiramente }\end{array}$ & & & & & & $\begin{array}{l}\text { Concordo } \\
\text { inteiramente }\end{array}$ \\
\hline & 1 & 2 & 3 & 4 & 5 & 6 & 7 \\
\hline \multirow{2}{*}{$\begin{array}{l}\text { 4. A fadiga interfere } \\
\text { no meu desempenho } \\
\text { físico. }\end{array}$} & $\begin{array}{l}\text { Discordo } \\
\text { inteiramente }\end{array}$ & & & & & & $\begin{array}{l}\text { Concordo } \\
\text { inteiramente }\end{array}$ \\
\hline & 1 & 2 & 3 & 4 & 5 & 6 & 7 \\
\hline \multirow{2}{*}{$\begin{array}{l}\text { 5. A fadiga causa-me } \\
\text { problemas } \\
\text { frequentes. }\end{array}$} & $\begin{array}{l}\text { Discordo } \\
\text { inteiramente }\end{array}$ & & & & & & $\begin{array}{l}\text { Concordo } \\
\text { inteiramente }\end{array}$ \\
\hline & 1 & 2 & 3 & 4 & 5 & 6 & 7 \\
\hline \multirow{2}{*}{$\begin{array}{l}\text { 6. A minha fadiga } \\
\text { impede um } \\
\text { desempenho físico } \\
\text { prolongado. }\end{array}$} & $\begin{array}{l}\text { Discordo } \\
\text { inteiramente }\end{array}$ & & & & & & $\begin{array}{l}\text { Concordo } \\
\text { inteiramente }\end{array}$ \\
\hline & 1 & 2 & 3 & 4 & 5 & 6 & 7 \\
\hline \multirow{2}{*}{$\begin{array}{l}\text { 7. A fadiga interfere } \\
\text { com a execução de } \\
\text { certas obrigações e } \\
\text { responsabilidades. }\end{array}$} & $\begin{array}{l}\text { Discordo } \\
\text { inteiramente }\end{array}$ & & & & & & $\begin{array}{l}\text { Concordo } \\
\text { inteiramente }\end{array}$ \\
\hline & 1 & 2 & 3 & 4 & 5 & 6 & 7 \\
\hline \multirow{2}{*}{$\begin{array}{l}\text { 8. A fadiga é um dos } \\
\text { três sintomas mais } \\
\text { incapacitantes que } \\
\text { tenho. }\end{array}$} & $\begin{array}{l}\text { Discordo } \\
\text { inteiramente }\end{array}$ & & & & & & $\begin{array}{l}\text { Concordo } \\
\text { inteiramente }\end{array}$ \\
\hline & 1 & 2 & 3 & 4 & 5 & 6 & 7 \\
\hline \multirow{2}{*}{$\begin{array}{l}\text { 9. A fadiga interfere } \\
\text { no meu trabalho, } \\
\text { na minha vida } \\
\text { familiar ou } \\
\text { na minha vida social }\end{array}$} & $\begin{array}{l}\text { Discordo } \\
\text { inteiramente }\end{array}$ & & & & & & $\begin{array}{l}\text { Concordo } \\
\text { inteiramente }\end{array}$ \\
\hline & 1 & 2 & 3 & 4 & 5 & 6 & 7 \\
\hline
\end{tabular}




\section{IBM (Índice de Barthel Modificado)}

\begin{tabular}{|c|c|c|}
\hline \multicolumn{3}{|c|}{ ÍNDICE DE BARTHEL MODIFICADO } \\
\hline ITEM & & SUBTOTAL \\
\hline ALIMENTAÇÃO & $\begin{array}{l}\text { 1. Dependente. Precisa ser alimentado. } \\
\text { 2. Assistência ativa durante toda tarefa. } \\
\text { 3. Supervisão na refeição e assistência para tarefas associadas (sal, manteiga, fazer o prato). } \\
\text { 4. Independente, exceto para tarefas complexas como cortar a carne e abrir leite. } \\
\text { 5. Independente. Come sozinho, quando se põe a comida ao seu alcance. Deve ser capaz de fazer as } \\
\text { ajudas técnicas quando necessário. }\end{array}$ & \\
\hline HIGIENE PESSOAL & $\begin{array}{l}\text { 1. Dependente. Incapaz de encarregar-se da higiene pessoal. } \\
\text { 2. Alguma assistência em todos os passos das tarefas. } \\
\text { 3. Alguma assistência em um ou mais passos das tarefas. } \\
\text { 4. Assistência mínima antes e/ou depois das tarefas. } \\
\text { 5. Independente para todas as tarefas como lavar seu rosto e mãos, pentear-se, escovar os dentes, e } \\
\text { fazer a barba. Inclusive usar um barbeador elétrico ou de lâmina, colocar a lâmina ou ligar o } \\
\text { barbeador, assim como alcançá-las do armário. As mulheres devem conseguir se maquiar e fazer } \\
\text { penteados, se usar. }\end{array}$ & \\
\hline $\begin{array}{l}\text { USO DO } \\
\text { BANHEIRO }\end{array}$ & $\begin{array}{l}\text { 1. Dependente. Incapaz de realizar esta tarefa. Não participa. } \\
\text { 2. Assistência em todos os aspectos das tarefas. } \\
\text { 3. Assistência em alguns aspectos como nas transferências, manuseio das roupas, limpar-se, lavar as } \\
\text { mãos. } \\
\text { 4. Independente com supervisão. Pode utilizar qualquer barra na parede ou qualquer suporte se o } \\
\text { necessitar. Uso de urinol à noite, mas não é capaz de esvaziá-lo e limpá-lo. } \\
\text { 5. Independente em todos os passos. Se for necessário o uso de urinol, deve ser capaz de colocá-lo, } \\
\text { esvaziá-lo e limpá-lo. }\end{array}$ & \\
\hline BANHO & $\begin{array}{l}\text { 1. Dependente em todos os passos. Não participa. } \\
\text { 2. Assistência em todos os aspectos. } \\
\text { 3. Assistência em alguns passos como a transferência, para lavar ou enxugar ou para completar } \\
\text { algumas tarefas. } \\
\text { 4. Supervisão para segurança, ajustar temperatura ou na transferência. } \\
\text { 5. Independente. Deve ser capaz de executar todos os passos necessários sem que nenhuma outra } \\
\text { pessoa esteja presente. }\end{array}$ & \\
\hline $\begin{array}{l}\text { CONTINÊNCIA DO } \\
\text { ESFÍNCTER ANAL }\end{array}$ & $\begin{array}{l}\text { 1. Incontinente } \\
\text { 2. Assistência para assumir a posição apropriada e para as técnicas facilitatórias de evacuação. } \\
\text { 3. Assistência para uso das técnicas facilitatórias e para limpar-se. Frequentemente tem evacuações } \\
\text { acidentais. } \\
\text { 4. Supervisão ou ajuda para por o supositório ou enema. Tem algum acidente ocasional. } \\
\text { 5. O paciente é capaz de controlar o esfíncter anal sem acidentes. Pode usar um supositório ou } \\
\text { enemas quando for necessário. }\end{array}$ & \\
\hline $\begin{array}{l}\text { CONTINÊNCIA DO } \\
\text { ESFÍNCTER } \\
\text { VESICAL }\end{array}$ & $\begin{array}{l}\text { 1. Incontinente. Uso de caráter interno. } \\
\text { 2. Incontinente, mas capaz de ajudar com um dispositivo interno ou externo. } \\
\text { 3. Permanece seco durante o dia, mas não à noite, necessitando de assistência de dispositivos. } \\
\text { 4. Tem apenas acidentes ocasionais. Necessita de ajuda para manusear o dispositivo interno ou } \\
\text { externo (sonda ou cateter). } \\
\text { 5. Capaz de controlar seu esfíncter de dia e de noite. Independente no manejo dos dispositivos } \\
\text { internos e externos. }\end{array}$ & \\
\hline VESTIR-SE & $\begin{array}{l}\text { 1. Incapaz de vestir-se sozinho. Não participa da tarefa. } \\
\text { 2. Assistência em todos os aspectos, mas participa de alguma forma. } \\
\text { 3. Assistência é requerida para colocar e/ou remover alguma roupa. } \\
\text { 4. Assistência apenas para fechar botões, zíperes, amarras sapatos, sutiã, etc. } \\
\text { 5. O paciente pode vestir-se, ajustar-se e abotoar toda a poupa e dar laço (inclui o uso de adaptações). } \\
\text { Esta atividade inclui o colocar de órteses. Podem usar suspensórios, calçadeiras ou roupas abertas. }\end{array}$ & \\
\hline $\begin{array}{l}\text { TRANSFERÊNCIAS } \\
\text { (CAMA E CADEIRA) }\end{array}$ & $\begin{array}{l}\text { 1. Dependente. Não participa da transferência. Necessita de ajuda (duas pessoas). } \\
\text { 2. Participa da transferência, mas necessita de ajuda máxima em todos os aspectos da transferência. } \\
\text { 3. Assistência em algum dos passos desta atividade. } \\
\text { 4. Precisa ser supervisionado ou recordado de um ou mais passos. } \\
\text { 5. Independente em todas as fases desta atividade. o paciente pode aproximar da cama ( com sua } \\
\text { cadeira de rodas ), bloquear a cadeira, levantar os pedais, passar de forma segura para a cama, virar- } \\
\text { se, sentar-se na cama, mudar de posição a cadeira de rodas, se for necessário para voltar e sentar-se } \\
\text { nela e voltar à cadeira de rodas. }\end{array}$ & \\
\hline
\end{tabular}




\begin{tabular}{|c|c|c|}
\hline ITEM & & SUBTOTAL \\
\hline $\begin{array}{c}\text { SUBIR E DESCER } \\
\text { ESCADAS }\end{array}$ & $\begin{array}{l}\text { 1. Incapaz de usar degraus. } \\
\text { 2. Assistência em todos os aspectos. } \\
\text { 3. Sobe e desce, mas precisa de assistência durante alguns passos desta tarefa. } \\
\text { 4. Necessita de supervisão para segurança ou em situações de risco. } \\
\text { 5. Capaz de subir e descer escadas de forma segura e sem supervisão. Pode usar corrimão, bengalas e } \\
\text { muletas, se for necessário. Deve ser capaz de levar o auxílio tanto ao subir quanto ao descer. }\end{array}$ & \\
\hline DEAMBULAÇÃO & $\begin{array}{l}\text { 1. Dependente na deambulação. Não participa. } \\
\text { 2. Assistência por uma ou mais pessoas durante toda a deambulação. } \\
\text { 3. Assistência necessária para alcançar apoio e deambular. } \\
\text { 4. Assistência mínima ou supervisão nas situações de risco ou período durante o percurso de } 50 \\
\text { metros. } \\
\text { 5. Independente. Pode caminhar, ao menos } 50 \text { metros, sem ajuda ou supervisão. Pode usar órtese, } \\
\text { bengalas, andadores ou muletas. Deve ser capaz de bloquear e desbloquear as órteses, levantar-se e } \\
\text { sentar-se utilizando as correspondentes ajudas técnicas e colocar os auxílios necessários na posição de } \\
\text { uso. }\end{array}$ & \\
\hline $\begin{array}{l}\text { MANUSEIO DA } \\
\text { CADEIRA DE } \\
\text { RODAS } \\
\text { (ALTERNATIVO } \\
\text { PARA } \\
\text { DEAMBULAÇÃO) }\end{array}$ & $\begin{array}{l}\text { 1. Dependente na ambulação em cadeira de rodas. } \\
\text { 2. Propulsiona a cadeira por curtas distâncias, superfícies planas. Assistência em todo o manejo da } \\
\text { cadeira. } \\
\text { 3. Assistência para manipular a cadeira para a mesa, cama, banheiro... } \\
\text { 4. Propulsiona em terrenos irregulares. Assistência mínima em subir e descer degraus, guias. } \\
\text { 5. Independente no uso de cadeira de rodas. Faz as manobras necessárias para se deslocar e } \\
\text { propulsiona a cadeira por pelo menos } 50 \mathrm{~m} \text {. }\end{array}$ & \\
\hline & TOTAL & \\
\hline
\end{tabular}

\section{Escala Numérica de Dor de 11 Pontos}

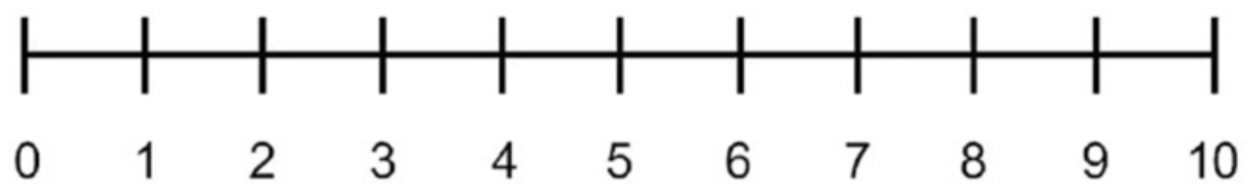

Sem Dor

Pior Dor

Possível 


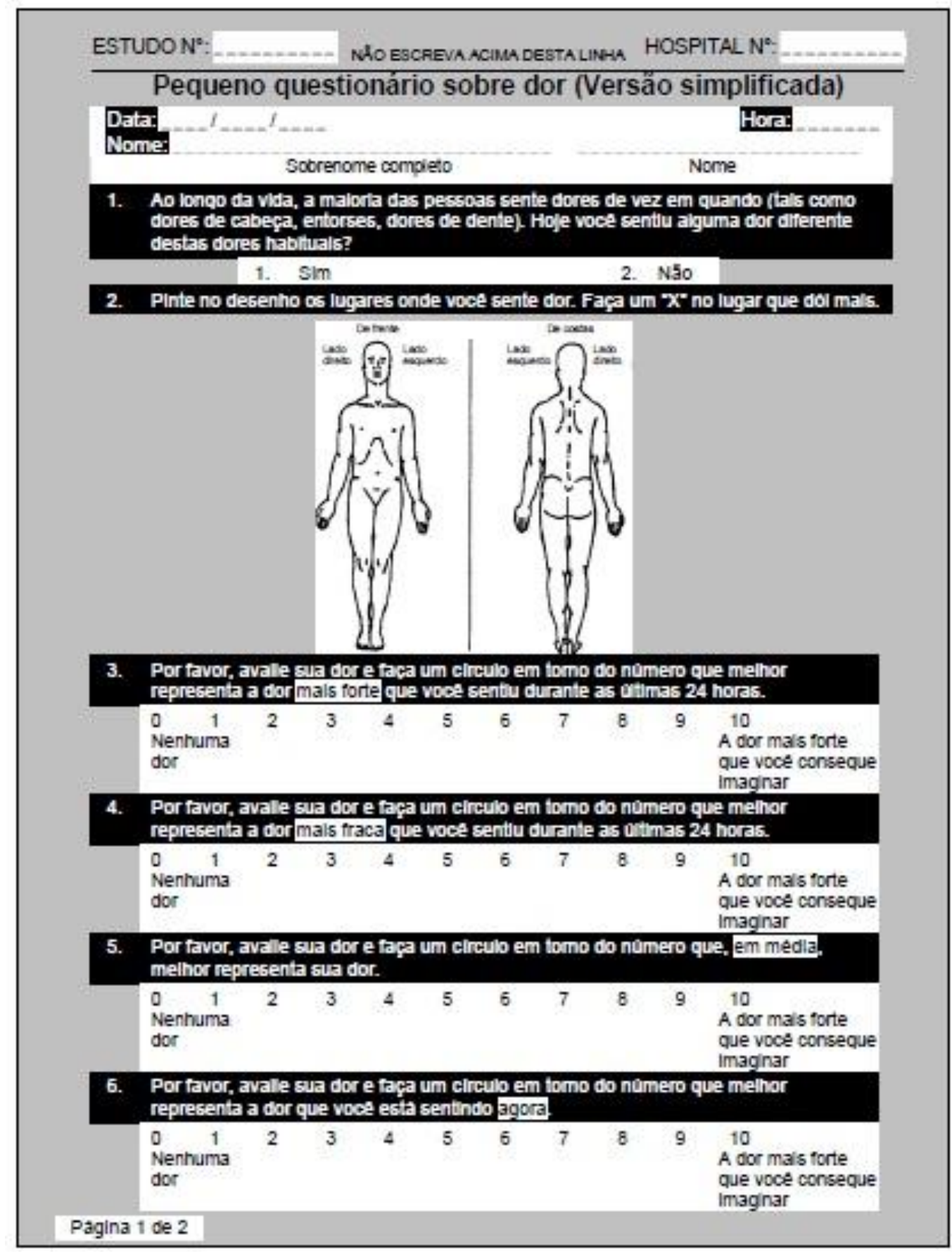

BPI-SF - Brazl Portuguese - September 26, 2005 


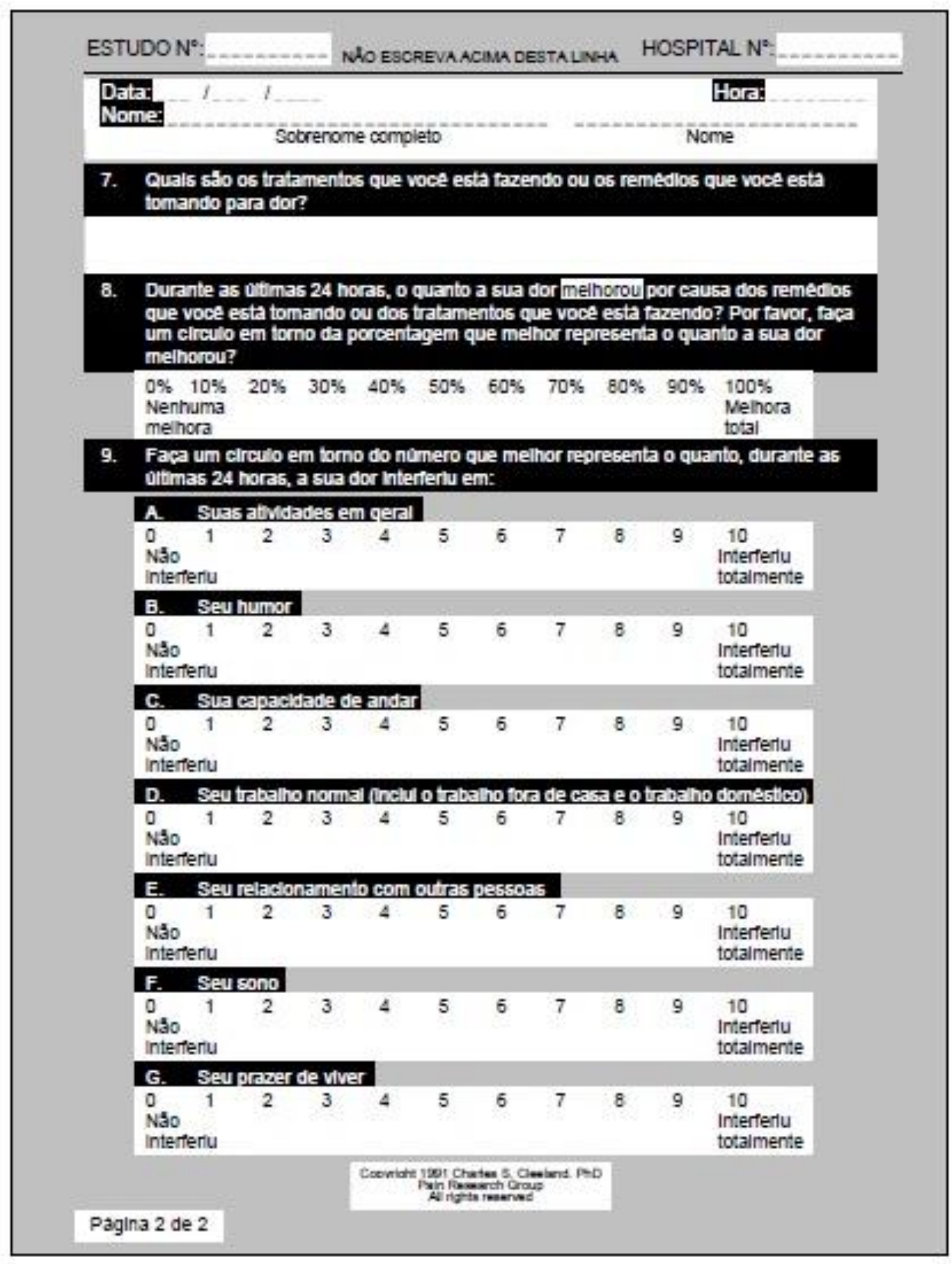




\section{PCS (Escala de Pensamentos Catastróficos sobre Dor)}

Escala de Pensamento Catastrófico sobre a Dor (B-PCS)

\begin{tabular}{|c|c|c|c|c|c|c|}
\hline & $\begin{array}{l}\text { Nome: } \\
\text { Escolaridade (anos completos de estudo, e }\end{array}$ & $\begin{array}{l}\text { Ide: } \\
\text { cluir mobr }\end{array}$ & \multicolumn{2}{|c|}{ Sexo: $\square \mathrm{M} \square \mathrm{F}$} & Data: & \\
\hline & \multicolumn{6}{|c|}{$\begin{array}{l}\text { Instruções: } \\
\text { Listamos } 13 \text { declarações que descrevem diferentes pensamentos e sentimentos que podem lhe aparecer na } \\
\text { cabeça quando sente dor. Indique o GRAU destes pensamentos e sentimentos quando está } \\
\text { com dor }\end{array}$} \\
\hline 1 & $\begin{array}{l}\text { A preocupação durante todo o tempo com a duração da dor } \\
\text { é }\end{array}$ & $\begin{array}{c}0 \\
\text { Minima }\end{array}$ & $\begin{array}{c}1 \\
\text { leve }\end{array}$ & $\stackrel{2}{2}$ & $\begin{array}{c}3 \\
\text { Intensa }\end{array}$ & $\begin{array}{c}4 \\
\text { Muito intensa }\end{array}$ \\
\hline 2 & O sentimento de não poder prosseguir (continuar) é & $\begin{array}{l}0 \\
\text { Mínimo }\end{array}$ & $\begin{array}{c}1 \\
\text { leve }\end{array}$ & $\stackrel{2}{\text { Moderado }}$ & $\begin{array}{c}3 \\
\text { Intenso }\end{array}$ & $\begin{array}{l}4 \\
\text { Muito intenso }\end{array}$ \\
\hline 3 & O sentimento que a dor é terrivel e que não vai melhorar é & $\begin{array}{c}0 \\
\text { Minimo }\end{array}$ & $\begin{array}{c}1 \\
\text { leve }\end{array}$ & $\begin{array}{c}2 \\
\text { Moderado }\end{array}$ & $\begin{array}{c}3 \\
\text { Intenso }\end{array}$ & $\begin{array}{l}4 \\
\text { Muito intenso }\end{array}$ \\
\hline 4 & $\begin{array}{l}\text { O sentimento que a dor é horrivel e que você não vai } \\
\text { resistir é }\end{array}$ & $\begin{array}{c}0 \\
\text { Mínimo }\end{array}$ & $\begin{array}{c}1 \\
\text { leve }\end{array}$ & $\begin{array}{c}2 \\
\text { Moderado }\end{array}$ & $\begin{array}{c}3 \\
\text { Intenso }\end{array}$ & $\begin{array}{c}4 \\
\text { Muito intenso }\end{array}$ \\
\hline 5 & O pensamento de não poder mais estar com alguém é & $\begin{array}{c}0 \\
\text { Mínimo }\end{array}$ & $\begin{array}{c}1 \\
\text { leve }\end{array}$ & $\stackrel{2}{\text { Moderado }}$ & $\begin{array}{c}3 \\
\text { Intenso }\end{array}$ & $\stackrel{4}{4}$ \\
\hline 6 & O medo que a dor pode se tornar ainda pior é & $\begin{array}{c}0 \\
\text { Mínimo }\end{array}$ & $\begin{array}{c}1 \\
\text { leve }\end{array}$ & $\begin{array}{c}2 \\
\text { Moderado }\end{array}$ & $\begin{array}{c}3 \\
\text { Intenso }\end{array}$ & $\begin{array}{c}4 \\
\text { Muito intenso }\end{array}$ \\
\hline 7 & O pensamento sobre outros episódios de dor é & $\begin{array}{c}0 \\
\text { Minimo }\end{array}$ & $\begin{array}{c}1 \\
\text { leve }\end{array}$ & $\stackrel{2}{\text { Moderado }}$ & $\begin{array}{c}3 \\
\text { Intenso }\end{array}$ & $\begin{array}{c}4 \\
\text { Muito intenso }\end{array}$ \\
\hline 8 & O desejo profundo que a dor desapareça é & $\begin{array}{c}0 \\
\text { Mínimo }\end{array}$ & $\begin{array}{c}1 \\
\text { leve }\end{array}$ & $\stackrel{2}{\text { Moderado }}$ & $\begin{array}{c}3 \\
\text { Intenso }\end{array}$ & $\begin{array}{c}4 \\
\text { Muito intenso }\end{array}$ \\
\hline 9 & O sentimento de não conseguir tirar a dor do pensamento é & $\begin{array}{c}0 \\
\text { Mínimo }\end{array}$ & $\begin{array}{c}1 \\
\text { leve }\end{array}$ & $\stackrel{2}{\text { Moderado }}$ & $\begin{array}{c}3 \\
\text { Intenso }\end{array}$ & $\begin{array}{c}4 \\
\text { Muito intenso }\end{array}$ \\
\hline 10 & O pensamento que ainda poderá doer mais é & $\begin{array}{c}0 \\
\text { Minimo }\end{array}$ & $\begin{array}{c}1 \\
\text { leve }\end{array}$ & $\stackrel{2}{\text { Moderado }}$ & $\begin{array}{c}3 \\
\text { Intenso }\end{array}$ & $\begin{array}{c}4 \\
\text { Muito intenso }\end{array}$ \\
\hline 11 & $\begin{array}{l}\text { O pensamento que a dor é grave porque ela não quer parar } \\
\text { é }\end{array}$ & $\begin{array}{c}0 \\
\text { Minimo }\end{array}$ & $\begin{array}{c}1 \\
\text { leve }\end{array}$ & $\stackrel{2}{\text { Moderado }}$ & $\begin{array}{c}3 \\
\text { Intenso }\end{array}$ & $\begin{array}{l}4 \\
\text { Muito intenso }\end{array}$ \\
\hline 12 & $\begin{array}{l}\text { O pensamento de que não há nada para fazer para diminuir } \\
\text { a intensidade da dor é }\end{array}$ & $\begin{array}{c}0 \\
\text { Minimo }\end{array}$ & $\begin{array}{c}1 \\
\text { leve }\end{array}$ & $\stackrel{2}{\text { Moderado }}$ & $\begin{array}{c}3 \\
\text { Intenso }\end{array}$ & $\begin{array}{l}4 \\
\text { Muito intenso }\end{array}$ \\
\hline 13 & $\begin{array}{l}\text { A preocupação que alguma coisa ruim pode acontecer por } \\
\text { causa da dor é }\end{array}$ & $\begin{array}{c}0 \\
\text { Mínima }\end{array}$ & $\begin{array}{c}1 \\
\text { leve }\end{array}$ & $\stackrel{2}{\text { Moderado }}$ & $\begin{array}{c}3 \\
\text { Intenso }\end{array}$ & $\begin{array}{c}4 \\
\text { Muito intenso }\end{array}$ \\
\hline
\end{tabular}




\section{Escala de Brooke}

\section{Escala de Brooke}

A capacidade funcional do paciente é classificada em um dos 6 itens:

\begin{tabular}{|c|c|}
\hline 1 & $\begin{array}{l}\text { Inicia com os MMSS ao lado do corpo, é capaz abduzir os braços em uma amplitude de movimento } \\
\text { completa até alcançar acima da cabeça. }\end{array}$ \\
\hline 2 & $\begin{array}{l}\text { É capaz de levantar os braços acima da cabeça apenas flexionando os cotovelos (diminuindo a } \\
\text { amplitude de movimento) ou usando músculos acessórios. }\end{array}$ \\
\hline 3 & $\begin{array}{l}\text { Não é capaz de levantar as mãos acima da cabeça, mas pode levantar um copo de água de } 237 \mathrm{ml} \text { até a } \\
\text { boca (usando ambas as mãos se necessário). }\end{array}$ \\
\hline 4 & É capaz de levar a mão à boca, mas não é capaz de levantar o copo de água de $237 \mathrm{ml}$ até a boca. \\
\hline 5 & $\begin{array}{l}\text { Não é capaz de levar a mão à boca, mas pode usar a mão para segurar uma caneta ou pegar moedas em } \\
\text { cima da mesa. }\end{array}$ \\
\hline 6 & Não é capaz de levar a mão à boca, não possui função com as mãos. \\
\hline
\end{tabular}

(BROOKE et al, 1981)

\section{Escala de Vignos}

\section{Escala de Vignos modificada por Brooke}

A capacidade funcional do paciente é classificada em um dos 10 itens:

\begin{tabular}{|c|l|}
\hline $\mathbf{1}$ & Deambula e sobe escadas sem auxílio \\
\hline $\mathbf{2}$ & Deambula e sobe escadas com ajuda de corrimão \\
\hline $\mathbf{3}$ & $\begin{array}{l}\text { Deambula e sobe escadas vagarosamente, com ajuda de corrimão (mais de 25 } \\
\text { segundos para 8 degraus) }\end{array}$ \\
\hline $\mathbf{4}$ & Deambula sem assistência e levanta da cadeira, mas não consegue subir escadas \\
\hline $\mathbf{5}$ & Deambula sem assistência, mas não consegue levantar da cadeira ou subir escadas \\
\hline $\mathbf{6}$ & Deambula somente com auxílio ou deambula independentemente com tutor longo \\
\hline $\mathbf{7}$ & Deambula com tutor longo, mas requer auxílio para manter o equilíbrio \\
\hline $\mathbf{8}$ & $\begin{array}{l}\text { Permanece na posição ortostática com o tutor longo, mas não é capaz de andar sem } \\
\text { auxílio }\end{array}$ \\
\hline $\mathbf{9}$ & Confinado à cadeira de rodas \\
\hline $\mathbf{1 0}$ & Confinado ao leito \\
\hline
\end{tabular}

(VIGNOS JR; SPENCER JR; ARCHIBALD, 1963) 